Rev. Elev. Méd. Vét. Poys trop., 1966, 19, 2 (169-212).

\title{
Les Glossines vectrices des Trypanosomiases au Tchad
}

\author{
par J. GRUVEL \\ RÉSUMÉ
}

Les Trypanosomiases, humaınes ou animales, ainsi que leurs principaux vecteurs, les Glossines, n'ont cessé de préoccuper les Médecins et Vétérinaires depuis leur présence au Tchad, dès le début du siècle.

- L'éfude de cette importante question des Glossines vectrices des Trypanosomiases au Tchad se présente sous la forme d'une mise ou point et comprend quatre parties.

- La premıère examine l'impartance des Trypanosomiases au Tchad et expose l'historique des recherthes sur ce sujet.

- La deuxième est entièrement consacrée aux Glossines. Elle indique tout d'abord les acquisitions d'enquêtes anciennes et la progression faite dans la connaissance de leur répartition jusqu'en 1960. Ensuite, elle donne les résultats des prospections effectuées depuis 1962 et consccrées à l'étude de la distribution des espèces rencontrées au Tchad.

La réparhtion de chacune des trois espèces tchadiennes $G l$. tochınoides W'. Gl. fuscipes fuscipes N., Gl. morsitons submorsitons N., est également précisée.

- La troisième indique les principales remarques écologiques faites au cours des prospections qui, dons une certaine mesure, peuvent expliquer la répartition actuelle des Glossines.

- 17 Cartes, dont une générale hors texte, 3 tableaux, 2 schémas, 8 photos ef 16 références biblıographiques complètent cette élude des Glossınes au Tchad.

\section{I. - GÉNÉRALITÉS}

Io Importance des Trypanosomiases.

a) Importance historique.

Les Trypanosomiases rencontrées en Afrique tropicale sont des affections parasitaires comptant parmi les plus graves et les plus répondues des maladies de ces régions.

Elles y sont connues certainement depuis l'Antiquité. On savait alors que dans diverses parties de ce continent et à certaines saisons, le bétail était tué par des piqures «empoisonnées » de mouches qui pouvaient ainsi rendre l'élevage impossible. Cette constatatıon faite constamment depuis l'historien et géographe grec AGATHARCHIDE (150 ans avant Jésus-Christ) conserve encore aujourd'hui toute sa valeur. Ces mouches «empoisonnées », ces «mouches qui tuent» comme l'on dit dans certains villages de brousse auraient enrayé la poussée vers le Sud des Mahométans et constituent encore au $X X^{e}$ siècle l'un des obstacles principaux à l'extension de l'élevage en Afrique.

Avec le Paludisme chez l'Homme, la Peste bovine ef la Péripneumonie chez les animaux, les Trypanosomiases constituent en Afrique des maladies de premier intérêt. 
En 1929, le Docteur Vétérınaire MALBRANT résume ainsi l'ımportance des Trypanosomiases:

«Les problèmes que ces affections ont posés « et posent encore à l'Afrique et notamment au «Tchad sont multiples. Avant que de retarder «la pénétration ef la colonisation européennes, «elles ont d'abord largement contribué à entra«ver le progrès'social et économique de nom«breuses régions en y rendant impossible l'éle«vage qui constitue normalement la première «phase de l'évolution et la mise en valeur d'un «pays primitif et peu peuplé. Ce sont elles qui «ont obligé et obligent encore, là où l'auto«mobile n'a pu pénétrer, à avoir recours au «portage humain. C'est à elles enfin qu'est lié « le problème alimentaire qui se pose dans toutes « les régions équatoriales où l'élevage des ani«maux de boucherie est rendu impossible à « cause des tsé-tsés. C'est dire quelle importance "les Trypanosomiases ef leurs dangereux vec«teurs présentent en A. E. F.»

Par leurs effets, les Trypanosomiases sont done doublement nuisibles d̀ l'Homme : en l'affectant directement (Maladie du sommeil) ef indirectement en atteignant les animaux domestiques qu'll utilise.

\section{b) Importance des Trypanosomiases humaines ef} animales au Tchad : aspecf économique.

Les Trypanosomiases sont connues partout au Tchad et affectent I'Homme ef les Animaux domestiques.

La Trypanosomiase cameline, due à Trypanosoma evansi se rencontre partout au Nord du 13 e parallèle ef sa transmission est assurée mécaniquement, principalement par les Tabanidae. Partout ailleurs, vers le Sud, existent la Maladie du sommeil et la Trypanosomiase du bétail dontle principal vecteur est la Glossine ou Mouche tsé-tsé.

Seules ces dernières, liées à la présence de cette mouche, nous intéressent ici. Chaque dialecte du Sud possède un mot pour désigner les Glossines ; les Saras M'Boye les appellent Cong Mbah. les Saras Laka OuN'Kel, les Saras N'Gambaye Seldjé ef les Bananas Soussou-Felle. Mais les noms les plus répandus sont ceux donnés par les pasteurs nomades: Guah par les Foulbés et surtout Bodjéné donné par les Arabes du Tchad.

La Maladie du sommell a été étudiée en Afrique Centrale dès 1906 par la Mission MARTIN-
LEBOEUF-ROUBAUD. A cette époque, la frontière Tchad-Oubangui-Chari était située aux environs du $10^{\mathrm{e}}$ parallèle. Des villes telles que Pala, Kélo, Moundou, Fort-Archambault, n'appartenaient pas encore au Tchad. Ce n'est qu'en 1935 que la frontière actuelle entre ces deux territoires d'Afrique Centrale a été tracée (Carte $n^{0}$ 1). Les foyers de maladie étalent alors signalés principalement dans le Nord de l'actuelle R. C. A. Au Tchad, on ne connaissait que quelques foyers dissémınés le long du Chari et de ses affluents: plus particulièrement sur le cours supérieur du bahr Ouham à la frontière de la R. C. A. Elle était considérée comme rare et les auteurs écrivaient : «Afin d'éviter que la Trypanosomiase «humaine ne se répande dans la région non « infestée (Tchad), il serait nécessaire d'établir « un poste de surveillance à Fort-Crampel ; sur«veillance qui aurait un double but:

«- empêcher à Crampel les indigènes du Chari « d'entrer en contact avec les indigènes de «l'Oubangui ;

$\ll$ - examiner tous les indigènes se dirigeant «vers le Tchad pour retenir ceux qui sont « suspects. .»

Les travaux de BiOUILLIEZ (1916) sont plus précis et constituent réellement les premières recherches, sur la Maladie du sommeıl au Tchad. La zone de forțe endémicité de la maladie s'étalait depuis Goré jusqu'à Fort-Archambault, axée sur la Nana Barya ef le bahr Ouham, appelé bahr Sara près de son confluent.

En 1922, MURAZ entreprit de déterminer la limite Nord de la maladie en A. E. F. Ses travaux confirment ceux de BOUILLIEZ et les complètent : la zone d'endémicité s'étendant depuis Goré jusqu'au confluent des deux Logone, à une cinquantaine de kilomètres au Nord de Doba.

En dehors des enquêtes de JAMOT dans le bassin du Bas Logone au Nord-Cameroun et à Logone-Birni en particulier, où existe encore un foyer non négligeable, il n'est fait nulle part mention de la Maladie du sommeil dans la région du Bas Chari aux environs et en aval de FortLamy. Quelques communications personnelles permettent cependant d'affirmer que la maladie existait àl l'étał endémique sur. les bords du Chari (à Fort-Lamy même), du Serbewel et du Taf-taf. 
Certains villages déciarés maudits étaient alors fréquemment abandonnés.

Depuis 1947, les enquêtes sur la Maladie du sommeil ont été menées régulièrement dans tout le Territoire et de nombreux foyers ont été détectés et traités.

Vers 1950, le Service des Grandes Endémies du Tchad entreprit systématiquement le dépistage et le traitement par lomidinisation de tous les trypanosomés reconnus. Les enquêtes réalisées depuis cette date montrent que les régions les plus atteintes par la maladie appartiennent aux Préfectures du Logone oriental, du Logone occidental, du Chari-Baguirmi et du Moyen-Chari. Quelques cas seulement sont décelés au MayoKebbi. L'efficacité de la lutte menée contre la Trypanosomiase humane par le Service des Grandes Endémies est très appréciable. Depuis 5 ans, aucun nouveau cas n'a été enregistré dans la région du Bas-Chari (de Fort-Lamy au Lac Tchad) où pourtant les tsé-tsés abondent.

Dans les dix dernières années, le nombre total des examens n'a falt qu'augmenter tandis que le nombre de nouveaux trypanosomés dimınuait très sensiblement. Ainsi, en 1954, on comptait 285.996 personnes examinées et 439 nouveaux cas contre 819.066 examınés et 94 nouveaux cas en 1964. En dix ans, le nombre d'examens a presque triplé alors que le nombre de nouveaux malades dimınuait de près de cinq fois.

Ces résultats sont donc parfaitement encourageants et l'on peut supposer qu'à l'avenır ıls seront maintenus ou améliorés.

La trypanosomiase animale, mise en évidence au Tchad, dès 1901 par le Docteur MOREL sur des chevaux de Fort-Lamy, a été ensuițe décelée dans le Sud du Territoire par les recherches de RUELLE, KERMORGANT, KERANDEL. DepuIs, les vétérınares MAMET (1912), PECAUD (1915), DUGUÉ (1929), MALBRANT (1934) ef RECEVEUR (1948) se sont attachés à l'étude de cette affection en recherchant les principaux foyers, en précisant leur importance et en essayant différents traitements.

Avec la peste bovine et la péripneumonie, elle constitue encore le souci majeur des éleveurs ef des vétérinaires. Moins spectaculaıre, la trypanosomiase animale (bovine principalement) doit être considérée cependant comme la maladie la plus grave affectant l'élevage tchadien. Alors que la peste agit brutalement, tue rapidement ef laisse les survivants immunisés, la trypanosomiase est le plus souvent chronique, insidieuse et facilite l'installation d'autres maladies, infectieuses ou parasitaires sur ies animaux qu'elle a affaiblis. Les pertes qu'elle occasionne sont importantes bien que difficiles à chiffrer. La mortalité très variable est relativement peu élevée dans l'ensemble ; par contre, le nombre d'animaux atteints, amaigris, affaiblis et en conséquence improductifs ou inutilisables esi considérable. De plus, chaque animal trypanosomé joue le rôle d'un réservoir de virus dont la propagation peut être ensuite assurée par n'importe quel insecte hématophage.

La trypanosomiase du bétail existe au Tchad à l'état enzoótique partout où se rencontre la mouche tsé-tsé et partout où, en son absence, la transmission mécanique par d'autres Insectes Diqueurs peut être assurée. En conséquence, l'aire de répartition de cette maladie dépasse largement celle des Glossines et s'étend au-delà du Lac Tchad (Bol, N'Gouri, Rig-Rig et même Bokoro) ainsi que dans la région du Lac Fittrı.

Un arrêté du 7 novembre 1952 fixe les zones et les routes du bétail déclarées insalubres du fait des trypanosomiases.

L'importance des foyers est difficile à précıser et souvent très variable. Les Préfectures du Chari-Baguirmi, du Mayo-Kebbi, du MoyenChari, des Logone, sont d'après les enquêtes effectuées, les plus atteintes. Cependant, dans la région du Salamat, moins accessible aux dépistages, les pertes sonł loin d'être néglıgeajlas. Toure la région d'Am-Djelat situés au Sud. Ouest d'Am-Tıman a dô être récemmenì abandonnée par ses habitants en raison de la mortalité, voisine de 95 p. 100, qui affectait leurs troupeaux.

La trypanosomiase animale se manifeste princıpalement chaque année à la fin de la salson des pluies ef au début de la sasson sèche, au moment des grandes inondations, soit d'août à janvier. Les Glossines occupent alors leur aire d'extension maximum et les autres Insectes piqueurs, Tabanidae et Stomoxyinae sont partoui très abondants.

Certaines années opparaissent plus favorables au développement de la maladıe et il est curieux de constater une certaine périodicité d'environ 
cinq ans. Ainsi, les années 1924, 1929,1934,1939, 1946, 1950, 1956, 1961 sont celles qui comptent le plus de victimes. Elles correspondent en effet à des pluies particulièrement abondantes et à des crues exceptionnelles du Chari et de ses affluents.

Quelques estimations relatives à la seule trypanosomiase bovine au Tchad sont résumées dans le tableau no 1.

\section{TABIEAU NOI}

Trypanosomiase bovine au Tchad

\begin{tabular}{|c|c|c|c|}
\hline Années & Notobre de foyers & $\begin{array}{c}\text { Nombre de } \\
\text { maladeg* }\end{array}$ & Mortalite \\
\hline 1950 & 129 & 14.651 & - \\
1951 & 132 & 10.699 & - \\
1952 & 121 & 7.801 & - \\
1953 & 307 & 19.844 & - \\
1954 & 537 & 15.219 & 7.422 \\
1955 & 1.429 & 35.641 & 10.075 \\
1956 & nombreux foyers & 55.224 & - \\
1957 & nombreux foyers & 52.924 & - \\
1958 & nombreux foyers & 39.797 & - \\
1959 & - & - & - \\
1960 & - & - & - \\
1961 & nombreux foyers & 100453 & 11.066 \\
1962 & nombreux foyers & 87.104 & 11.483 \\
1963 & nombreux foyers & 79.003 & 6.580 \\
\hline
\end{tabular}

* Ces chiffres sont donnéa sous toute réserve en raigon de la difficulté qu'il $\mathrm{y}$ a à préciser le nature exacte de la maladie ou la cause de la mort, la recherche de trypanosones n'ayant pas été toujours systématiquement faite.

Les trypanosomes transmis par les mouches tsé-tsés appartiennent aux trois groupes: vivax, brucel et congolense. Trypanosoma congolense est le plus fréquent avec un pourcentage de $45,8 \mathrm{p}$. $100 ; T$. vivax se rencontre dans 42 p. 100 des examens et $T$. brucei est plus rare : 12 p. 100 des cas.

Le cheptel bovin tchadien évalué à 4 millions de têtes $a$ environ la moitié de son effectif exposé aux atteintes de la trypanosomiase en raison des séjours effectués dans les zones dangereuses. Ces séjours sont imposés en saison sèche par la recherche de l'eau ou de pâturages qui oblige les éleveurs à se rendre dans des régions qu'ils ne fréquenteraient pas autrement.

Le dépistage des animoux malades et les traitements curatifs ou prophylactiques s'effectuent encore d'une manière incomplète. Si quelques éleveurs demandent parfois le traitement de leurs animaux, la plupart des troupeaux échappent d̀ toute investıgation, leurs propriétaires évitant tout contact avec les services officiels. Les quelques résultats numériques que l'on possède sont donc loin de refléter la réalité et y sont très inférieurs. Au total, un maximum de 100.000 bovins est traité chaque année (suspects ef malades) ce qui représente actuellement une dépense d'environ 3 millions de Francs CFA.

\section{$2^{\circ}$ Les vecteurs des trypanosomiases.}

En tant qu'Insecte piqueur, la mouche tsé-tsé est connue depuis fort longtemps et dès le début du $X \mid X e$ siècle ses descriptions sont nombreuses.

Depuis les travaux de BRUCE (1897) préclsant le rôle de cette mouche dans la biologie et la transmission des trypanosomes, on lul attribue à juste titre un rôle fondamental dans la propagation des trypanosomiases. Mais il est classiquement reconnu que d'autres Diptères hématophages : Tabanides, Stomoxes, Hippobosques, peuvent également transmettre mécaniquement les trypanosomes d'un animal malade à un animal sain à l'occasion de repas de sang interrompus.

Ce falt, qui explique la propagation de la maladie dans des troupeaux, situés hors des zones à Glossines, est particulièrement vérifiable au Tchad où il était déjà signalé dès 1912 par MAMET : «ll semble bien démontré que les « tsé-tsés ne doivent pas être considérées comme «les seuis agents susceptibles de transmettre «la maladie; d'après les observations et les «travaux récents de nombreux auteurs, Il est «prouvé que les Tobonus et les Stomoxys peuvent « servir d'intermédiaires. »

Cette étude est limitée à la répartition des Glossines et à l'examen de quelques aspects de leur écologie.

\section{Il. - DISTRIBUTION DES GLOSSINES $A U$ TCHAD}

\section{Historique.}

a) Enquêtes antérieures d̀ 1929 (Carte no 1).

Dès leur installation au Tchad, militaires, médecins et vétérinaires se sont intéressés aux trypanosomiases et plus particulièrement à leur principal vecteur, la mouche tsé-tsé. Leur action, depuis le début du siècle, a déjà été évoquée plus haut. Devant la nécessité d'aménager le 
Retour au menu

LES FOYERS DE MOUCHES TSETSES AU TCHAD AVANT 1929

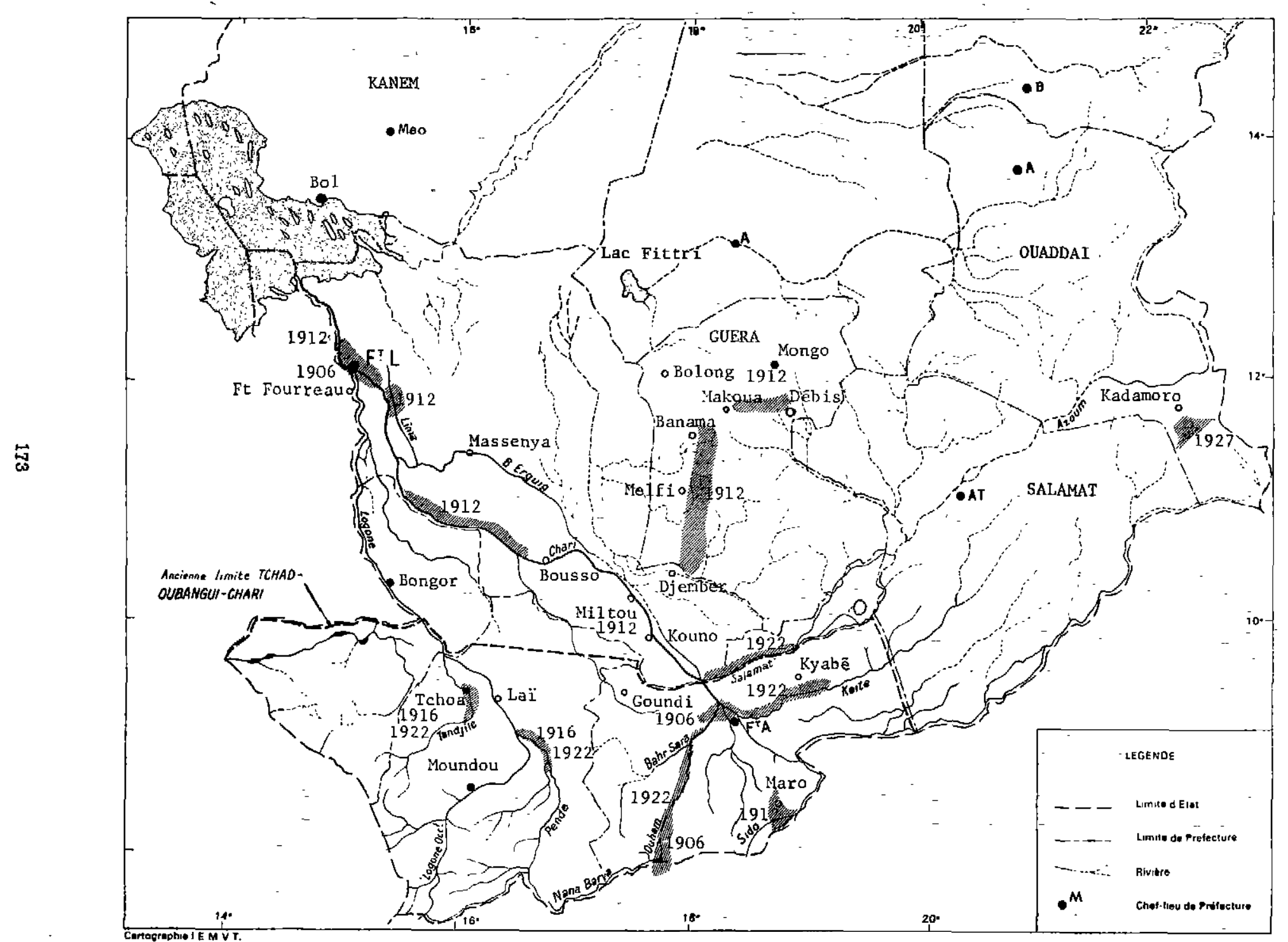


territoire, de tracer des pistes, d'ınstaller des gîtes d'étape, d'assurer les déplacements du bétail et d'utiliser des pâturages, ils se sont souvent heurtés à la présence de cette mouche dont le rôle maléfique était déjà trop connu. Les connaissances relatives aux régions infectées furent d'abord fragmentaires et réduites aux déclarations des éleveurs nomades. CeuX-CI connaissaient depuis fort longtemps les zones où se trouve la Glossine ef savaient le plus souvent les éviter soigneusement. Ensuite, de nombreux rapports signalent les lieux infestés et recommandent, soit le débroussaillement des zones de passage, soit des itinéraires détournés permettant d'éviter le contact avec la tsé-tsé.

La Mission MARTIN-LEBOEUF-ROUBAUd, étudiant la Maladie du sommeil dans le Sud du Tchad vers 1906, note la présence de Glossina morsitans, la plus abondante, sur l'Ouham (dans sa portion située en R. C. A. et à Manda près de Fort-Archambault ; de Gl. tachinaides sur le Chari aux environs de Fort-Archambault et dans la région de Fort-Lamy et de Gl. palpalis, ces deux espèces étant considérées comme rares. Ce dernier fait est intéressant à remarquer car l'espèce appelée autrefois $G$. palpalis, sans autre précision et qui est en réalité $G$. fuscipes fuscipes Newstead 1910, est actuellement très répandue dans le Sud du Tchad, notamment sur la Pendé, sur le Logone occidental et dans toutes les galerie forestières situées entre ces deux fleuves.

En mars 1912, une circulaire du colonel LARGEAU recommande d'établir des cartes de répartıtion des tsé-tsés. On trouve dès cette époque un rapport du lieutenant FRANCESCHI concernant l'établissement de gîtes d'étape dans la région du Guéra, sur la route de Mongo à Boulong, qui sıgnale la présence de mouches tsé-tsés dans tout le canton de Dabra (entre Mongo et Mahoua), près de Débir, au Sud-Ouest de ce village et sur le bahr Banda. Cette région constitue actuellement la limite Nord de Glossina morsitans submorsitans $N$.

La même année (décembre), dans la région du Moyen-Chari, le capitaine MARTIN recommande de suivre pour les déplacements du bétail vers Fort-Archambault, les trajets suivants :

- du Salamat à F-Archambault par Koré, Kyabé, Marabé :
- de Lai à F-Archambault par Goundi et Dobo ;

- de F-Archambault à Fort-Crampel par Cadbré, Maro.

Ce dernier itinéraıre est étudié par ailleurs en 1913 par le lieutenant VIAN qui préconise des débroussaillements aux niveaux de : Mougoudanga, Maro, Baguirguf, Sido, Bô, villages situés à proximıté de galeries forestières infestées de tsé-tsés. Ces trajets sont encore valables de nos jours car ils traversent des régions où les glossines sont absentes ou peu nombreuses.

Dans le Chari-Baguirmi plusieurs zones dangereuses sonf signalées (GONNET, décembre 1912). Subdivision de Massénya : les abords du bahr Erguig, la rive gauche du Chari jusqu'à Bousso, le bahr Linıa sont infestés. Les seuls pâturages possibles étant situés au Nord et à l'Est de Massénya.

Les accès à la subdivision de Melfí ne peuvent se faire que par l'Ouest, le Nord-Ouest et le Sud-Ouest ; c'est là que se trouvent les troupeaux car il n'y a aucune tsé-tsé. Toute la région de Melfi, à l'Estd'une ligne Banama, Melfí, Djember est dangereuse et à éviter.

Dans la subdivision de Miltou, toutes les routes : Miltou-Laï, Miltou-Kouno et MiltouMelfi sont infestées de mouches qui, en saison sèche, restent contonnées aux abords du Chari et des bahrs adjacents.

Pour la région de Fort-Lamy, MAMET (1912) précise que les mouches sont présentes sur les deux rives du Chari et de l'espèce $G$. tachinordes. Dans la ville même elles sont abondantes. Dès 1921, leur régression dans cette région est déjà mentionnée : «Le débossement à peu près total « de la ville a fait disparaître ces glossines qui «se réfugient sur la rive gauche du Charı ef du «Logone, autour de Kousseri (Fort-Foureau) où 《il existe de nombreux gîtes tous très infestés ».

A cette époque, deux espèces sont signalées : G. morsitans dans les régions de Melfi et Dobro ; $G$. tachinoides au bahr Linia et au bord du Chari.

PECAUD (1914) confirme la présence des tsétsés dans le bassin du Chari et le Sud du territoire du Tchad; il qualifie ces régions de dangereuses.

En 1916, le médecin major BOUILLIEZ effectue les premières recherches sur la maladie du sommeil au Tchad. II mentionne la présence de 
polpalis dans le Sud du pays ef établit une carte de répartition de la maladie.

MURAZ (1922) signale la présence des trois espèces tchadiennes dans le Sud et indique leurs gîtes dont les emplacements correspondent à peu près à ceux donnés par BOUILLIEZ :

- G. tachinoidessur la Tandjllé à Tchoa, Paet Tchakacéré; sur le Pendé aux abords du confluent des deux Logone; sur le bahr Sara, Chari et Bahr Salamat;

- G. palpalis sur la Pendé au niveau du confluent et sur le cours supérieur du bahr Sara ;

- G. morsitans sur la Pendé, bahr Keita et bahr Salamat. Ces gîtes correspondent à peu près à ceux rencontrés actuellement; mais l'abondance de $G$. palpalis sur le Logone occidental n'est pas encore signalée à cette époque.

Le premier rapport sur la région du Ouaddaï est dô au Docteur LEGAC : «La limite Nord de « Gl. morsitans estparallèle à I'Oued Koulbouti ; « il y a à peine quelques années la Glossine « ne dépassait pas la lımite du Dar-Fongoro. «Actuellement clle a pénétré dans le Dar-Signar « ef continue son ascension jusqu'au bahr « Azoum ».

En 1927, le Docteur MALVAL; chargé de I'A. M. I. ne partage pas l'opinion du Docteur LEGAC au sujet de «l'ascension » de G. morsitans et croit plutôt à une réduction de son aire d'extension. II ajoute : «Les Glossines sont au Fongoro depuis fort longtemps, rendant cette région peu peuplée et inhospitalıère au bétail. il n'y a pas de mouches dans le Galfigué, elles débordent à peine dans le Syniar. II ne semble pas que les mouches s'installent au bahr Azoum, ni sortent des limites connues déjà depuis longtemps. »

b) Carte MALBRANT ef RIQUIER (1929) (Carte $n^{\circ} 2$ ).

Il faut attendre 1929 pour avoir une Idée d'ensemble sur la répartition des Glossines au Tchad.

La carte établie en janvier 1929 ef publiée en

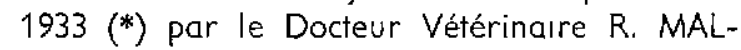
BRANT, alors Chef des Services Zootechniques au Tchad est malheureusement limitée aux frontières d'avant 1935. Elle ne donne donc que

* En collaboration avec J.-M. DUGUÉ. très peu de renseignements sur le Sud du Tchad actuel. Elle concerne la zone d'élevage tradıtionnel qui s'étend au Nord du $10 \mathrm{e}$ parallèle. Cette carte n'indique que la répartition des deux espèces : Gl. tachinordes $\mathrm{W}$. et $\mathrm{Gl}$. morsitans submorsitans N., Glossino fuscipes fuscipes $N$. étant localisée dans le Sud du Tchad qui appartenait autrefois à l'Oubangui-Chari. Pour les régions considérées, cette carte est dans l'ensemble encore très valable.

Elle signale dans le Sud-Ovest du Tchad les foyers des chutes Gauthiof sur la Mayo-Kebbi, de la Tandjilé et de la région Sud de Pala.

Sur le Logone, elle indique la présence de mauches tsé-tsés aux bords de la Pendé jusqu'au Sud de Dobc. Celles-ci ne se retrouvent qu'à une vingtaine de kilomètres au Nord de Bongor jusqu'aux environs de Kousseri (Fort-Foureau).

Le long du Chari, les Glossines sont partout présentes depuis Fort-Archambault jusqu'au Sud du Lac Tchad et s'étendent à l'intérieur aux environs de Mogroum par les affluents du Charl, Loumia et bahr Erguig. Elles ne sont signalées sur ce dernier cours d'eau que jusqu'à Moellem à l'Ouest de Massénya.

Au centre du Tchad, MALBRANT mentionne l'existence de tsé-tsés dans toute la région du Guéra, depuis le bahr Salamat jusqu'à Mongo. Dans la région d'Abou-Deïa, elles remontent le cours de l'Oued Zerab et du bahr Djourf.

A l'Est du Tchad, la carte de MALBRANT montre la présence de tsé-tsés depuis le bahr Salamat jusqu'à la frontière soudanaise sans toutefois dépasser au Nord une ligne sensiblement parallèle à une centaine de kilomètres au Sud du bahr Azoum.

La même année (mars 1929), le Docteur RlQUIER,Médecin Chef du Secteur de Fort-Archambault, présente une carte donnant la répartition des tsé-tsés dans la région située au Sud du ChariElle complète pour le Sud celle présentée par MALBRANT et ces deux cartes jointes donnent une idée générale de la distribution des Glossines au Tchad à cette époque. Cet Auteur signale quelques foyers de Glossines peu étendus ; bords du Chari dans la région Nord de Fort-Archambault, cours du bahr Keita, du bahr Ouham et le long de la Pendé jusqu'à Lai avec une interruption aux environs de Doba. La vallée du Mandoul constituant une dépression à peine marquée, marécageuse, est signalée comme infestée. 


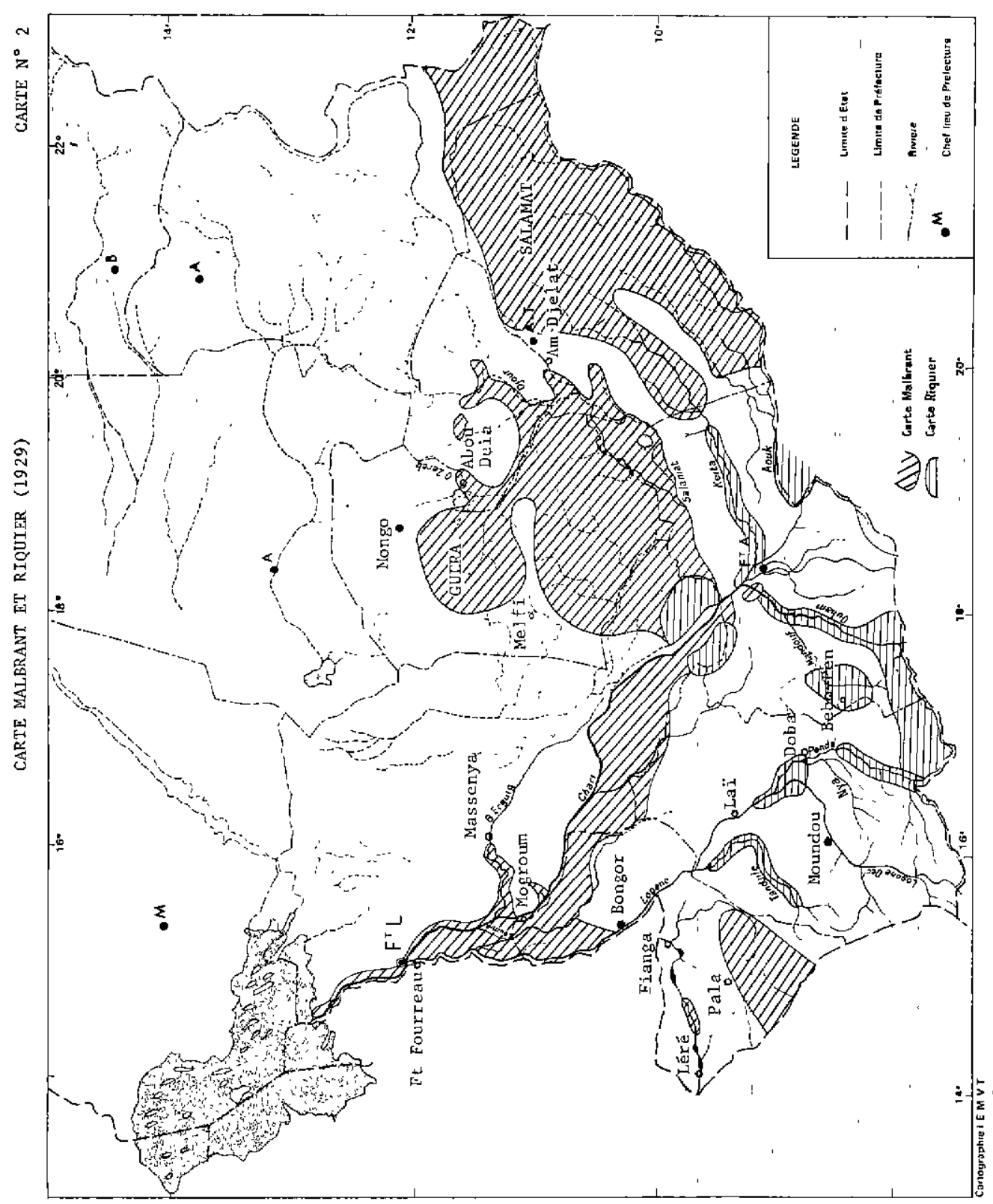




\section{c) Carte RECEVEUR (1948) (Carte no 3).}

En 1948, le docteur-vétérınaire P. RECEVEUR chef des Services vétérınaires au Tchad, publie une nouvelle carte de répartition des Glossines dons ce territoire.

Elle représente dans son ensemble toutes les données présentées par MALBRANT et les remarques faites plus haut sonf Ici encore valables.

Par rapport à la carte précédente, quelques variations sont à noter :

SUr le Bas-Logone, RECEVEUR ne signale les tsé-tsés que de Kholem au confluent, ce qui indique une régression par rapport d̀ 1929.

Cours du Chari et affluents. La répartition donnée par RECEVEUR est plus complète; elle mentionne la présence des tsé-tsés en amont de Fort-Archambault et sur les principaux affluents: bahr Keita, bahr Salamat, bahr Korbol, Batha de Laïri (en saison des pluies), bahr Sara ef Ba-IIIi. II soupçonne avec juste raison l'extensıon des Glossines à tout le bahr Erguig.

Partout ailleurs la distribution des tsé-tsés est la même sauf aux environs d'Abou-Deïa où l'Auteur ne signale pas de foyers sur l'Oued Zéreb ef donne une extension sur le bahr Djourf plus réduite.

Dans la région d'Am-Timan, il porte la limite plus au Nord, mais par contre la situe un peu plus au Sud dans le Sud-Ouadda.

La carte de RECEVEUR est donc superposable à celle de MALBRANT ; elle la complète dans le Moyen-Chari, à l'Est du Chari et la précise au Sud de Fort-Lamy et au Nord de Militou.

\section{d) Carte MAlllot (1953-6I) (Carte no 4).}

En 1953, puis en 1961, L. MAILLOT publie une carte générale de la répartition des Glossines dans les Etats de l'ancienne fédération d'A. E. F. : Gabon, Congo, République Centrafricaine et Tchad.

Cette carte a l'avantage de préciser la distribution de chacune des trois espèces tchadiennes. Elle a été établie d'une manière indirecte par renseignements et envois de captures à l'Auteur qui en a assuré les déterminations avec la collaboration de différents entomologistes. Dans certains cas les déterminations ont été faites par les captureurs eux-mêmes ce qui peut expliquer certaines erreurs importantes dans la répartition des espèces. De plus, le nombre de points de récoltes est assez faible et si cette carte reste valable à l'échelle africaine, elle est très imprécise pour le Tchad.

Glossina fuscipes fuscipes $N$. s'étend dans le Sud-Ovest du Tchad et. la carte indique pour lımite d̀ cette espèce une lıgne enveloppant au Nord les régions de Moundou et de Fort-Archambault. Une concavité centrale isole la cuvette du Mandoul qui apparaît ainsi indemne de mouches.

Glossina tachinoides $W$. déborde largement cette zone jusqu'à une ligne bordant à l'Est le cours du Chari depuis le Lac Tchad à la frontière R. C. A.

La distribution de Glossina morsitans submorsitans $N$. précisée par cette carte montre une vasle dispersion de cette espèce. A l'Est du $18^{\mathrm{e}}$ degré de longitude Est, la limite Nord ne dépasse pas le $11 \mathrm{e}$ parallèle ; à l'Ouest de ce méridien Mr MAILLOT indique quelques foyers en bordure du Chari aux environs de Fort-Lamy et jusqu'à Djimtilo près du Lac Tchad, sur le bahr Erguig aux environs de Massénya, sur le Logone depuis LogoneBirni jusquau confluent, sur le Logone occidental en aval de Moundou et aux environs de Fienga et Pala. Ces foyers'lui font remonter la limite Nord d'extension de cette espèce dans l'Ouest du Tchad jusqu'au Lac Tchad.

\section{$2^{\circ}$ Répartition actuelle des Glossines au Tchad.}

L'étude de la répartition des Glossınes présentée ici résulte d'enquêtes effectuées pendant trois années consécutives et qui ont été entièrement consacrées à cette question. Ces enquêtes ont été menées systématiquement à travers le Tchad, les déplacements étant réalisés par la route en saison sèche, par voie fluviale (Logone, Chari et affluents) en saison des pluies et pendant la période d'inondation qui lui succède. Au total, près de 25 mois on été consacrés à cette étude au cours desquels on peut estimer que 70.000 kilomètres ont été parcourus. Les renseignements pris auprès des habitants sont de quel que valeur lorsqu'ils sont positifs; dans le cos contraire, ce qui est le plus fréquent, il ne faut jamais tenir compte de leurs affirmations le plus souvent erronées. Seuls les pasteurs nomades connaissent bien la mouche tsé-tsé dont ils évitent le contact dans la mesure du possible.

Les limites de l'extension de chaque espèce ont aınsi pu être établies avec précision. 


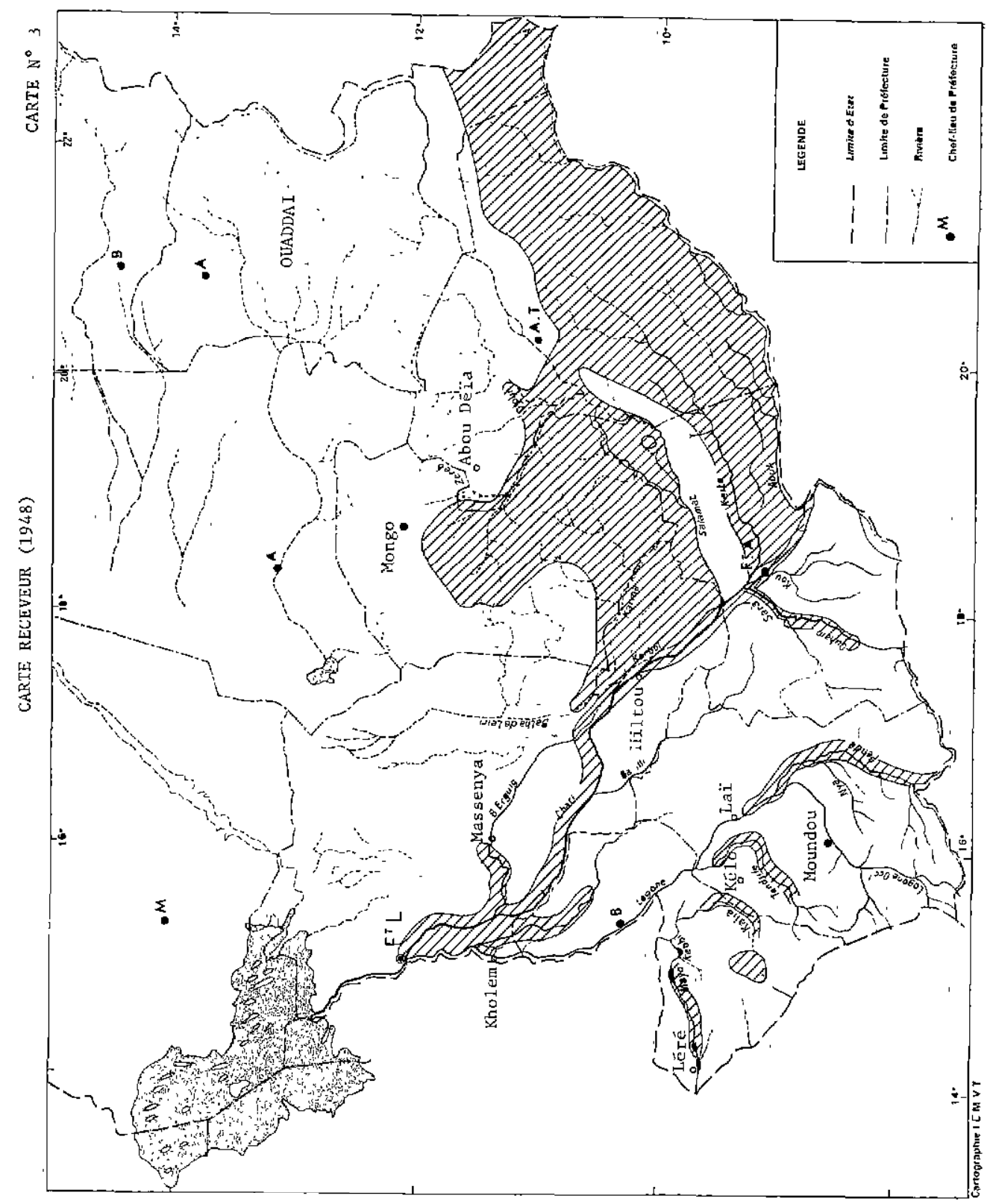




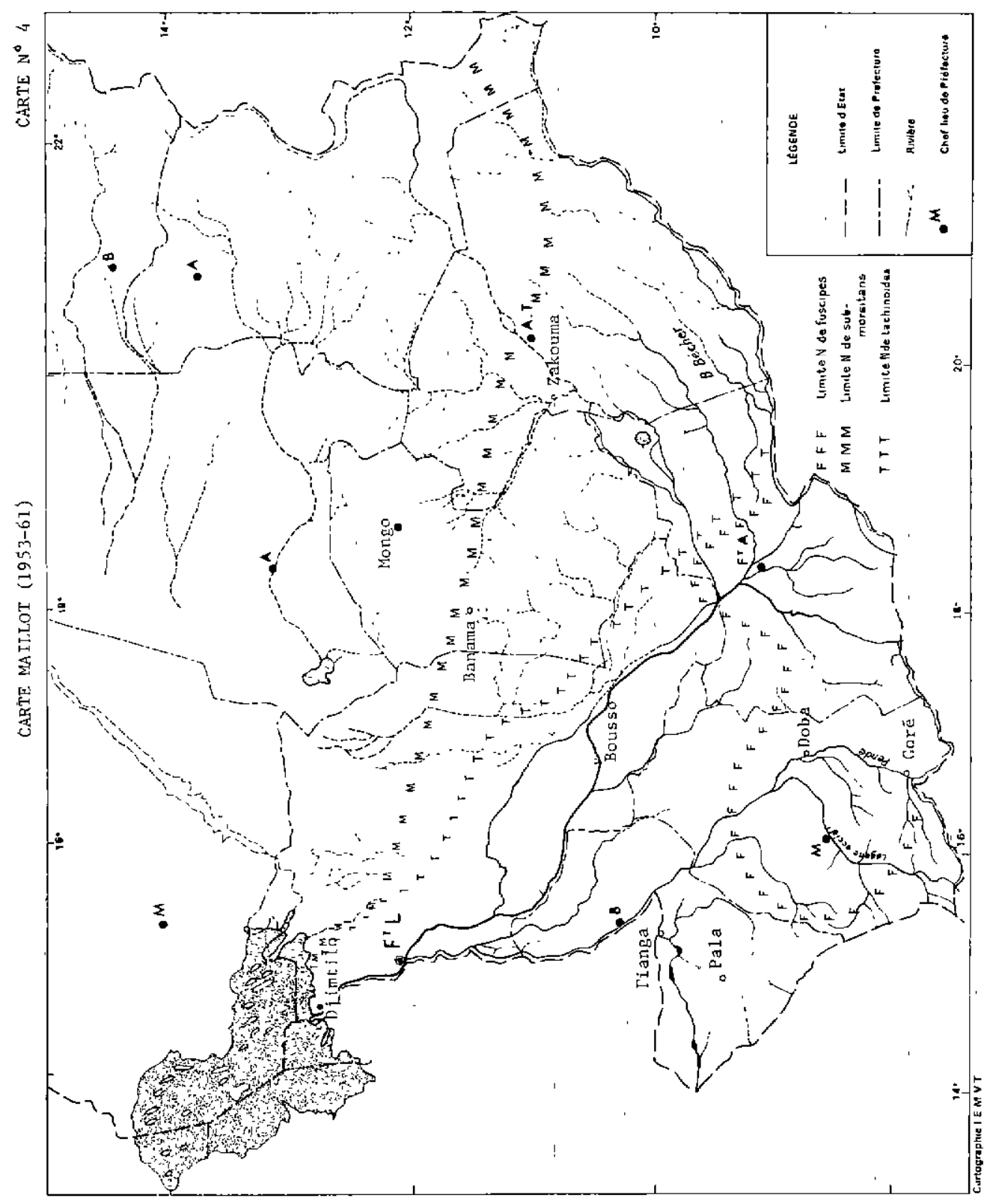


Chaque signe conventionnel représenté sur la carte générale représente un lieu de capture de Glossines.

a) Distribution générale des trois espèces tchadiennes. Données générales.

Les Glossines occupent au Tchad une surface entièrement siłuée au Sud du $12^{\mathrm{e}}$ parallèle. Seule une étroite bande est dirigée au Nord de celui-ci et correspond au cours du Chari, de Fort-Lamy au Lac Tchad, dont les galeries forestières retiennent une importante population de tsé-tsés.

Le territoire au Sud de ce $12^{\mathrm{e}}$ parallèle n'est pas totalement infesté et schématiquement les Glossines ne se rencontrent que dans une région détermınée par le réseau hydrographique (bassin du Chari et de ses affluents, bassin du Logone) à laquelle s'ajoute une bande centrale axée sur le méridien de Fort-Archambault et s'étendant vers le Nord sur une largeur d'environ 120 kilomètres depuis le bahr Salamat jusqu'au Sud de Mongo (Corte n० 5).

La limite Nord actuelle des Glossines au Tchad correspond à une ligne dont le tracé d'Ouest en Est est le suivant. A partir du Lac, la lımite suit la rive droite du Chari jusqu'à Bougoumène et la rive droite du bahr Erguig jusqu'aux abords du Batha de Lairi à partir duquel elle se continue le long du bahr Karma pour s'infléchir vers le Nord au niveau de Djember. De là, elle poursuit une direction à peu près Sud-Nord, par Melfi jusqu'au Sud de Bitkine au pied du Massif du Guéra. Elle s'incurve ensuite vers l'Est, puis le Sud - laissant au Nord le Massif de l'Aboutelfan et à l'Est la zone montagneuse d'AbouDeĩa - se prolongeant dans cette direction jusqu'au Sud de Djebren sur le bahr Korom. La limite se continue alors par une vaste courbe qui remonte vers le Nord-Est, englobant les deux-tiers de la réserve de Zakouma ef une partıe du bahr Djourf avant de prendre à l'Ouest d'Am-Timan la direction d'Haraze, ville au Sud de laquelle elle atteint la frontière de la République Centrafricaine.

La limite Nord de la tsé-1sé se retrouve ensuite à l'Est du Tchad, décrivant depuis la frontière R. C. A. une ligne sensiblement Nord-Sud située à l'Est des bahrs Babonksi et Diokana jusqu'à la latitude de Tédji. Elle prend alors une direction Ouest-Est jusqu'à la frontière du Soudan à une cinquantaine de kilomètres au Sud de Mongororo.

A l'intérieur de cette lımite, les Glossines ne sont pas partout également présentes (Carte n6).

Toute la région comprise entre Logone et Chari, limitée à l'Ouest par le Logone de Laï à Zymado, à l'Est par le Chari et le Ba-llli et au Sud par une ligne qui contourne par le Sud la dépression du Mandoul entre le bahr Ouham et la Pendé est exempte de tsé-tsés.

La zone comprise entre bahr Erguig et Char est également sans Glossines. Celles-ci restent cantonnées aux bords des fleuves et ne trouvent aucun affluent susceptible de favoriser leur extension vers l'intérieur.

La zone de savane entre Chari et Ba-Illi sépare les gîtes qui les bordent et est vide de mouches.

Une étroite bande dépourvue de mouches s'étend entre les bahrs Keita et Salamat depuis le Chari jusqu'au Sud-Ouest d'Am-Timan.

Les environs de Baïbokoum, légèrement montagneux et déboisés n'hébergent pas de mouches sur cinquante kilomètres vers le Nord et trente kilomètres vers l'Est.

Partout ailleurs les Glossines se rencontrent dans des foyers isolés ou groupés selon l'endroit considéré.

\section{Répartition géographique des Glossines.}

Trois espèces de Glossines existent au Tchad; elles appartiennent au groupe palpalis, sousgenre Nemorhina: Glossina tachinoides Westwood 1850, Glossino fuscipes fuscipes Newstead 1910 ef au Groupe morsitans, sous-genre Glossina : Glossina morsitans submorsitans Newstead 1910. Leur répartition peut être considérée suivant trois régions géographiques : le bassin du Charı avec ses affluents, le bassin du Logone et la région centrale du Guéra (Carte no 6 et carte générale),

\section{I) Bassin du Chari.}

Le fleuve traverse obliquement le Tchad en direction du Nord-Ouest jusqu'au Lac, sur près de 1.000 kilomètres. Constitué à son entrée au Tchad par la réunion du Bamingui et de l'Aouk, il reçoit successivement le bahr Keita, I'Ouham (bahr Sara), le bahr Salamat, le Ba-llli, le bahr Erguig, la Loumia. Enfin, au niveau de FortLamy, if reçoit le Logone et constitue alors le bassin du Bas-Chari. 


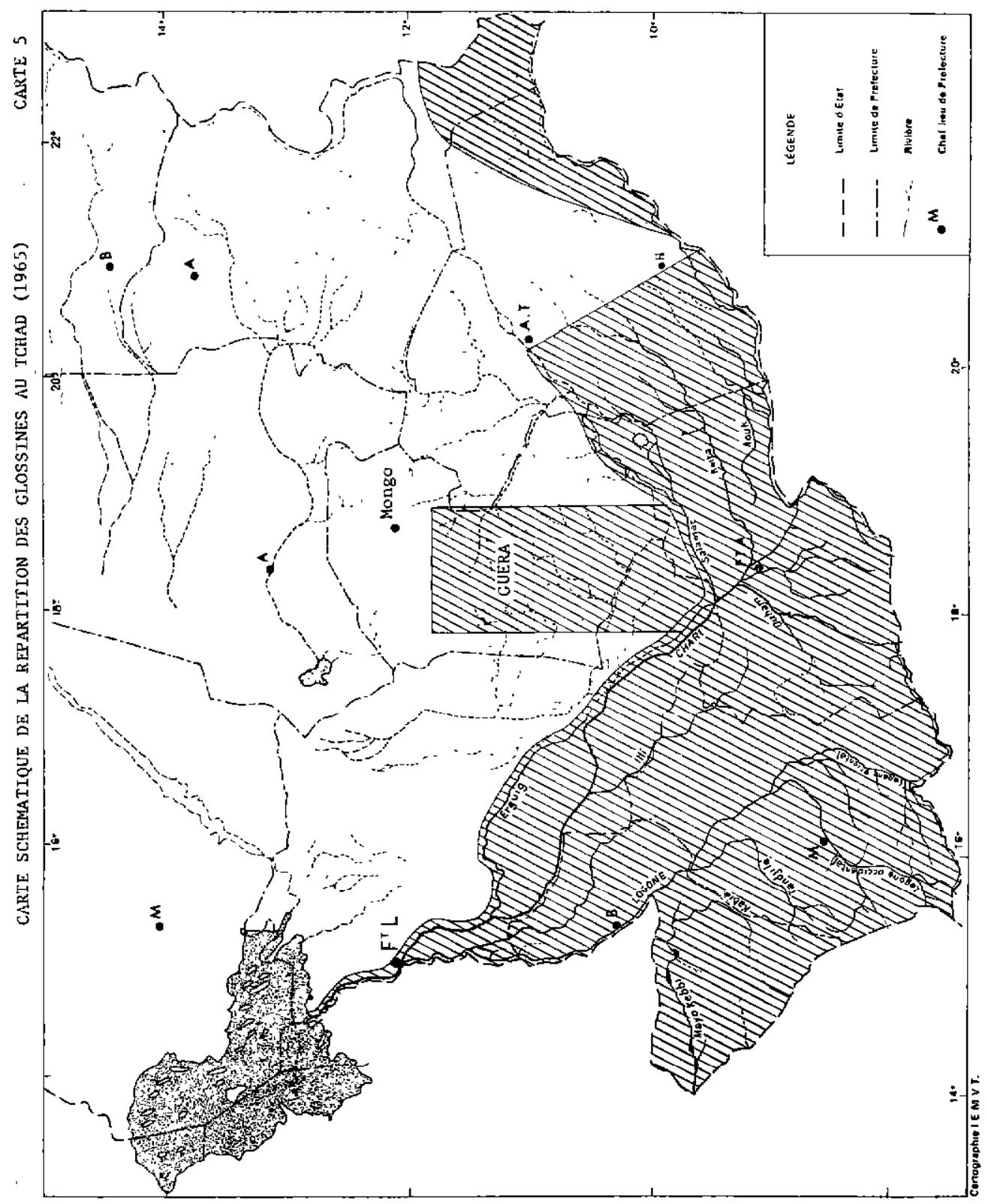




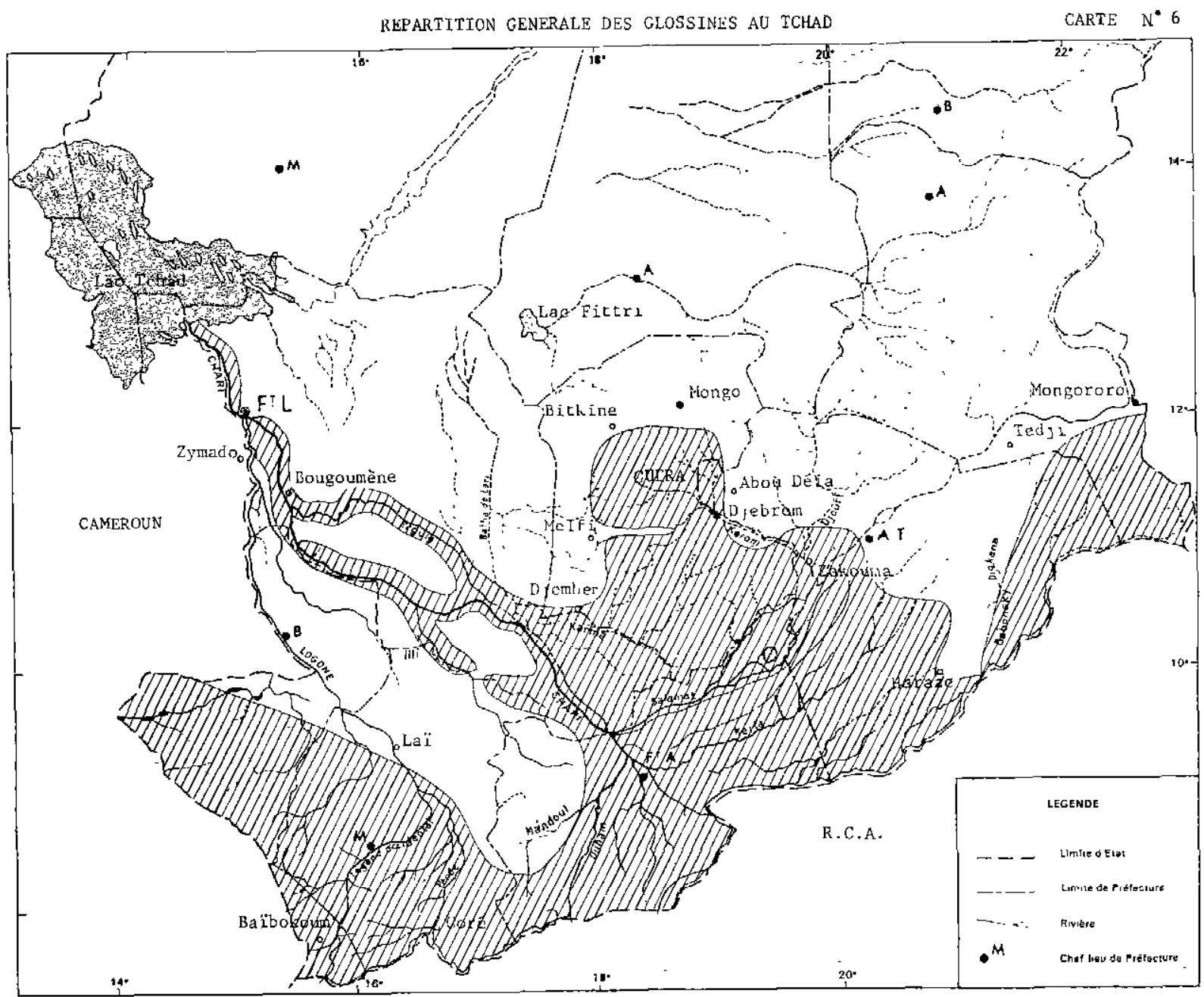




\section{Le Bas-Chari ; de Fort-Lamy au lac Tchad.}

Dans cette portion de son cours, le Chari détermine la frontière entre la République du Tchad et celle du Cameroun. Long de 150 kilomètres environ, il se présente sous deux aspects qui permettent de distinguer une partie sensiblement rectiligne de Fort-Lomy à Dougia ef une partie sinueuse, de Dougia au Lac où se développent de nombreux méandres.

Les deux rives du Chari sont ici presque constamment bordées de galeries forestières où les tsé-tsés (G. tachinoides) sont présentes. Seuls queiques espaces totalement déboisés ef mis en culture constituent des barrières naturelles séparant les différents gîtes. Durant ce trajet le Cnari reçoit deux cours d'eau camerounais : Serbewel et Taf-Taf qui le mettent en communication avec le lac Tchad. Ces deux affluents sont extrêmement riches en tsé-tsés et constituent de véritables réservoirs pour la région.

Les premières Glossines ne se rencontrent qu'à une quinzaine de kilomètres de Fort-Lamy, après Riggil sur la rive camerounaise. Elles $y$ sont très abondantes jusqu'au Serbewel; la rive tcnadienne est par contre à ce niveau totalement dénudée. Du Serbewel à Goulfey, on trouve deux petits gîtes à Gourmadjo et Mara, puis enfin les grands gîtes de Dro.

Sur 6 kilomètres de part et d'autre de Goulfey, les rives sont déboisées et n'offrent aucune possibilité de vie aux tsé-tsés.

Les Glossines sont ensuite partouł présentes jusqu'au Lac en inégale importance; les gîtes les plus importants étant ceux de Dougia, Mani et Djimtilo.

\section{Le Chari ; de Fort-Lamy à la frontière de la République Centrafricaine.}

Tout le cours du Chari est pratiquement infesté bien qu'à des degrés très divers.

De Fort-Lamy au bahr Erguig ; les premières mouches apparasssent dès Djlalı et existent, bien qu'en faible quantité, jusqu'à l'embouchure du bahr Erguig. Les principaux gîtes sont ceux. de Mogroum, Ash, Bougoumène et Meskine à I'embouchure de la Loumia. Cet affluent est fortement infesté sur la plus grande partie de son trajet.

Au confluent du bahr Erguig les tsé-tsés sont très abondantes (Mébı et Bilo) et remontent cet affluent sur tout son cours jusqu'à'l'endroit où celvi-ci rejoint le Chari. Seule une interruption de quelques kilomètres évite à Massénya tout contact avec la mouche.

Du bahr Erguig à Bousso, la densité des tsé-tsés est très faible. La rive droite, depuis Mandjaffa jusqu'à Onoko est indemne. Elle ne porte ensuite que quelques gîtes jusqu'à Bousso : Maojjoré, environs de Kaba et de Gadong-Kiao, Mafana et Lafana. La rive gauche, jusqu'à l'Ecole d'Agriculture du Ba-lili, présente peu de gîtes qui sont disséminés et ne gardent que peu de mouches : en amont de Mbéré, à Mosgougou ef aux environs de Berbéré. A partir de l'Ecole jusqu'au village du Ba-llli ef sur tout le cours d'eau du même nom, les Glossınes redeviennent extrêmement nombreuses. Les mouches remontent cet affluent jusqu'au village de Nakassao. Du BaIlli à Bousso la route suit le fleuve dont le bord est ici presque totalement débroussaillé.

De Bousso au confluent du bahr Ouham. La rive drolte porte à quelques kilomètres de Bousso les petits gîtes de Ngargé et de Mirti-Sara. Au Nord de Miltou, elle offre en profondeur un complexe hydrographique où les tsé-tsés sont abondantes mais disséminées. On trouve dès ce niveau $\mathrm{Gl}$. morsitons submorsistans $\mathrm{N}$. associée à Gl. tachinoides $W$., notamment sur le bahr Telabo. Cette région présente un intérêt particulier car y convergent la portion amont du bahr Erguig, au bahr Telabo ef le Batha de Laïri dont la continuité vers l'Est constitue le bohr Karma. Ces différents cours d'eau sont difficiles à dissocier et en période d'inondation cette région constitue un immense marais dont les formations végétales abritent un grand nombre de tsé-tsés. Aux environs de Korbol, le bahr Korbol est sans mouche; celles-a re se retrouvent en abondance qu'aux abords de Damtar (ou Damraou) près de Dik et en aval de Kouno. (Les deux importants affluents de la rive droite du Chari, le bahr Salamat et le bahr Keita seront étudiés plus loin avec l'ensembie hydrographique venant de l'Est.)

Lo rive gauche est peu infestée jusqu'à Dik : gîtes à l'Est de Gadang-Gougouri et aux envırons de Miltou, à partir de ce point et jusqu'à Fort-Archambault, deux espèces sont fréquentes (G. tochinoides et $G$. submorsitons) : gîtes de NielIım et de la réserve de Manda. A ce niveau, le Chari reçoit sur la rive gauche un important 
affluent, I'Ouham qui porte en fin de parcours le nom de Bahr Sara. Tout le trajet de ce cours d'eau est infesté de Gl. fachinoides jusqu'à la frontière, ainsi que ses petits affluents de la rive droite et plus particulièrement la Moula (avec quelques G. fuscipes) et le bahr Kou. Toute la zone comprise entre le Chari ef l'Ouham est rıche en tsé-tsés: $G$. tachinordes le long des cours d'eau ef $G$. submorsitans dans la savane, principalement auprès de la frontière de la République Centrafricaine. Le Mandoul, affluent gauche de l'Ouham a toujours été trouvé indemne de Glossines. Constituant un marécage parfaitement déboisé entre les bassins du Logone et du Chari il constitue un espace vide de mouches. Celles-ci ne se rencontrent qu'aux abords de la frontière, axées sur la Nana-Barya, déterminant ainsi une étroite bande reliant ces deux bassins.

Du confluent de l'Ouham jusqu'à la frontière, la portion du Haut-Chari ne présente plus que quelques gîtes : Hélibongo et Kemdéré aux environs de Fort-Archambault. II n'est cependant pas rare de trouver une Glossine errante dans la ville même, probablement transportée par un véhicule, une pirogue ou un vent favorable depuis le gîte le plus proche.

Les environs de la ferme de Moussafoyo hébergent de nombreuses $G$. tochinoides dont le point de rassemblement est situé sur la rive droite, face à la ferme.

En amont de Moussafoyo, le gîte le plus importont est celui de lala, à une dizaine de kilomètres, sur la rive gauche.

A l'Est et au Nord-Est de la région de FortArchambault, le bassin du Chari est constitué par le Bahr Aouk qui devient le Chari proprement dit après avoir reçu le Bamingui ef par deux affluents du Chari, le bahr Keita et le bahr Salamat.

Dans l'ensemble, loute la zone traversèe par ces trois éléments est très riche en Glossines. Celles-ci sont surtout abondantes le long du bahr Aouk et de I'Aoukalé jusque dans la région de Nzili. G. submorsitons domine et s'étend largement à l'intérieur en empruntant les nombreux affluents temporaires du cours d'eau principal ; $G$. tochinoides s'y rencontre aussi mais ne dépasse guère vers l'Est le confluent Aouk-Aoukalé.

La même remarque est valable pour les deux affluents du Chari, mais $G$. tachinoides y est plus fréquente que $G$. submorsitans. Sur le bahr Keita, leur limite Est est imprécise en rasson de la difficile pénétration de cette région, mais elle ne semble guère dépasser le $20^{\circ}$ degré de longitude Est.

Le bahr Salamat ef son affluent le bahr Bola entretiennent des petites populations de Glossines disséminées tout au long de leur cours. Comme précédemment, $G$. tachinoides est surtout présente vers le Chari ; à partir du lac iro, on rencontre de plus en plus fréquemment $G$. submorsitans qui devient l'espèce daminante. Cependant les deux espèces coexistent et se retrouvent en obondance sur tout le résecu hydrographique de la réserve de Zakouma. Dans cette région, G. tochinordes est limitée aux cours d'eau de la réserve tandis que G. submorsitans occupe la savane et s'étend plus à l'Est, sur le bahr Djourf aux environs d'EIOgna ef le long d'un petit affluent du bahr Salamat, l'Al-Delim, jusqu'à Am-Djélat. Ces derniers points constituent pour le réseau du Salamat la limite des Glossines, correspondant là aussi au $20^{\circ}$ Est.

En conséquence, la limite d'extension vers l'Est de la mouche tsé-tsé dans le bassin du Char peutêtre représentée par une ligne irrégulière qui part de l'Ouest d'Am-Timan parallèlement au méridien $20^{\circ}$ Est, s'infléchit vers l'Est à la hauteur de Djouna, reprend une direction Sud-Ovest après avoir enveloppé les gîtes de Mindjik et atteint la frontière aux environs de Ngolde il. Haraze se trouvant à l'extérieur de la limite.

La zone à tsé-tsés que l'on retrouve tout à fait à l'Est du Tchad peut être considérée comme dépendante du bassin du Chari par l'intermédiaire de l'Aoukalé qui reçoit les très nombreux petits cours d'eau qui la traverse.

Toutes les prospections possibles dans cette région montrent la présence de Gl. submorsitons sur l'oved, Seifou, le bahr Nzili, l'oued Simbi, l'oued Tireno, l'oued Nabagay.

Au Nord elles ne dépassent pas' le village de Kadomoro. Depuis Mongororo jusqu'à Aboukousoum, ainsi que jusqu'à Am-Timan, le bahr Azoum n'héberge aucune mouche. De même la route de Tedji à Makoua par Mangeigne, bordée en partie par le Diokana, traverse une région désertique où n'existe pas de tsé-tsé.

\section{2) Bassin du Logone.}

Au Sud de Fort-Lamy, le bassin du Logone n'est relié à celui du Chari qu'au niveau de la frontière de la R. C. A. par l'intermédiaire de la 
Nana-Barya et de son affluent le Boli. Ce tralt d'union entre les deux grands bassins fluviaux du Tchad est caractérisé par l'abondance des tsé-tsés dont les trois espèces sont réunies. Dans cette portion du territoıre, elles remontent au Nord jusqu'aux environs de Békourou.

Constitué par le Logone occidental et la Pendé (ou Logone oriental) qui se réunissent en amont de Laï, le Logone proprement dit s'écoule vers le Nord-Ouest, puis vers le Nord avant de se jeter dans le Chari. Depuis Ham (sur le $10^{3}$ parallèle) jusqu'à Fort-Foureau, il délimite la frontière entre le Tchad et le Cameroun. Son principal affluent est la Tandjilé qu'ıl reçoit sur la rive gauche. II est remarquable de constater que la Pendé et le Logone ne reçoivent aucun affluent sur leur rive droite, tous viennent de l'Ouest.

Le bassin est pauvre en Glossines; celles-cI n'existent qu'au Sud sur la Pendé et sur le Logone occidental, puis dans une courte galerie forestière présente pendant une soixantaine de kilomètres avant le confluent avec le Chari.

La Pendé. Depuis Goré jusqu'à Madana, G! tachinoides existe tout le long du Logone oriental en très forte densité. Elle est accompagnée de quelques $G$. submorsitons et de quelques $G$. fusctpes. Un éclaircissement de la végétation entre Béti et Doba rend cette portion indemne de mouches. D'une manière générale la densité des mouches est plus forte sur la rive gauche. Les affluents de la Pendé, le Mbango, le Mayo-Louté et la Nya portent des petites galeries où se trouvent, bien qu'en faible quantité, $G$. tochinoides et G. fuscipes.

Le Logone occidental. Avec son résecu d'affluents il constitue l'une des zones les plus riches en tsé-tsés du Sud du Tchad. Depuis une dizaine de kilomètres au Nord de Pandzangué jusqu'à sa jonction avec la Pendé, les formations végétales ripicoles sont très nombreuses et hébergent un grand nombre de $G$. fuscipes auxquelles s'ajoute $G$. tochinoides dons sa portion terminale. Cette région du Haut-Logone possède un réseau hydrographique très dense et chaque cours d'eau porte une petite galerie forestière oû $G$. fuscipes est toujours présente.

Seule la région de Baïbokoum limitée au Nord à la latitude de Laramanay et à l'Est suivant le méridien de Bésao, est dépourvue de Glossines.

La Tandjilé. Cet affluent du Logone traverse une zone très largement dénudée et ne retient qu'en de rares points une végétation suffisante au maintien des Glossines. G. tochinordes n'existe qu'aux environs de Bitikim, de Komadjia ef de Tchoa. Quelques foyers de G. fuscipes existent sur de petits affluents venant du Sud, à KrimKrim et à Beisa I. Les environs de la ferme de Déli sont également très infestés.

Le Logone proprement dit. Le dernier foyer de Glossines dans le Sud se situe peu après la rencontre du Logone occidental et de la Pendé, au village de Bara. Depuss ce point jusqu'à Zymado, à 60 kilomètres de Fort-Foureau, ies rives du Logone sont parfaitement déboisées et aucune tsé-tsé ne peut y vivre.

Les principaux foyers du Bas-Logone se situent de Zymado ò Kabé, soit sur environ 45 kılomètres. La végétation y est particulièrement abondante et les Glassines ( $G$. tachinoides) sont très nombreuses.

En annexe au bassın du Logone peut être examinée la région traversée par le Bạr Kabia ef le Mayo-Kebbi dont l'ensemble hydrographique s'éroule vers la Bénoué au Cameroun. Quelques G. tachmoides existent sur la Kabia entre Kardo et Zamré-Andar ainsı que sur le Mayo-Kebbi, des Chutes Gauthıot à Tréné, peu avant Léré. De même plus au Sud, près de Binder Nayré, puis sur le Mayo Sina aux environs de TagoboFoulbé, sur le Mayo Dari et le Mayo Banda Daïne vers Libetsornou.

Partout ailleurs, la savane est, dénudée et dépourvue de Glossines.

\section{3) Région du Guéra.}

Nous envisageons sous ce titre toute la zone définie plus haut par une bande large de $120 \mathrm{kilo-}$ mètres environ, axée sur le méridien de FortArchambault et s'étendant depuis le bahr Salamat jusqu'au Sud de Mongo.

Cette zone comprend au Nord, le, Guéra proprement dit, montagneux, dont le réseau hydrographique s'étale dans toutes les directions et au Sud une région de transition où se rencontrent encore quelques collınes mais dont l'ensemble est très légèrement incliné vers le Sud, entraînant ainsi tous les cours d'eau vers le bahr Salamat et la Mainé-Kondjo. (A ces régions ainsi définies se superposent les cortes au 1/200.000; dénommées « Guéra » et « Dagéla. »)

L'ensemble de cette région est couvert d'une savane claıre dont la densité n'augmente qu'aux 
abords des cours d'eau. Ceux-ci sont tous intermittents, débordant en saison des pluies, sans eau en saison sèche. Les Glossines, dont la seule espèce représentée est Gl. morsitans submorsitons, sont partout présentes. Plus abondantes au niveau des lits ombragés des bahrs, elles se répandent facilement dans la savane environnante, ce qui fait que toute la zone définie plus haut doit être considérée comme infestée.

Une étroite bande transversale Ouest-Est, axée sur la route de Melfi-Djebren, un peu au Nord du 10 parallèle, est parfaitement vide de tsé-tsés, du moins en saison sèche. Ceci peut s'expliquer si l'on remarque qu'elle n'est pratiquement traversée par aucun cours d'eau important ef que tous ceux des environs s'en écartent. Cette bande correspond donc d̀ une «ligne de partage des equx» et constitue une solution de continuité entre les deux grandes zones à tsé-tsés de la région examinée.

Dans la partie Nord les principaux gîtes sont ceux de Bidjir qui constituent le point le plus septentrional atteint par les mouches, ceux situés entre Bobo ef Banama ef ceux d'Abou-Dan (à I'Est de Banama) les plus occidentaux, puis ceux du Sud-Ouest de Dafra, de l'Ouest de Bourmatagil et de Djenda qui déterminent la lımite Est.

Partout à l'intérieur, G. submorsitans existe, répartie principalement aux abords des cours d'eau, Les environs de Diogou, de Temkı, de Koutouma et de Margoula sont particulièrement infestés.

Dans la partie Sud, tous les cours d'eau : Siaka, Danoa, Tourda, Koutoutou, Katanou, Elki, Douroum, Toundou-Kokélé, Mane-Kondjo sont fortement infestés, avec comme principaux lieux de capture les abords de la route Melfi Kendégué ; environs de Roukoum, Rim, Sısi, Timan, sur 10 à 15 kilomètres de profondeur. Par le Yanangourou et le Dankalou, les mouches s'étendent jusqu'au bahr Salamat.

A l'ouest, les tsé-tsés ne dépassent pas la route de Melfi Djember. A l'Est elles existent de Djebren à Koungouri, mais ne se trouvent plus vers Chingil et Karo. Elles réapparaissent vers l'Est, après Zan, sur le Yangara ; elles restent localisées à cette région ef n'atteignent pas le bahr Korom.

Le lac Fittri. Cette région du Tchad, située au Nord du $12^{\mathrm{e}}$ parallèle est depuis longtemps consi- dérée, à juste titre, comme un lieu où les infestations trypanosomiennes sont nombreuses. La maladie du sommeil n'y existe pas ; par contre, la trypanosomiase animale y est toujours importante. Pendant longtemps, la question s'est posée de savoir si les tsé-tsés existaient aux alentours de ce lac. Des opinions diverses et contradictoires ont été émises à ce sujet. Nous pouvons affirmer que les Glossines ne s'y trouvent pas. Aucun biotope n'est ici favorable d̀ leur maintien. La savane aborde le lac sous la forme d'une forêt claire à Acacia seyal et laisse rapidement la place à une dépression marécageuse, herbeuse, dans laquelle s'effectuent les variations de niveau du Fittri selon les périodes de l'année. Par contre, les Tabonidae sont extrêmement nombreux: Tabanus teaniola P. de B., Ancala fasciata nilotica $A$. pour ne citer que les plus fréquents, s'y trouvent toute l'anrée. La propagation des trypanosomiases animales ne doit être imputée qu'à eux seuls.

\section{Déplacements saisonniers des mouches tsé-tsés.}

Au cours de la saison des pluies et pendant la pérıde d'inondation qui lui succède, les Gloss1nes effectuent des déplacements localisés.

Les nouvelles conditions climatıques : dimınution de l'insolation ef surfout augmentation de l'hygrométrie permettent aux tsé-tsés de se déplacer sur de plus grandes distances sans souffrir de la déshydratation. D'une manière générale elles suivent le mouvement d'avancée et de recul des equx ; elles fuient leurs gîtes noyés et gagnent les zones ombragées de l'intérieur, trop sèches auparavant pour leur permettre de vivre.

Ces mouvements justifient queiques modifications dans le tracé des limites précédemment données.

Ainsi les Glossines du Bas-Charj s'étendent assez loin à l'intérieur, atteignant les mares ou marigots desséchés et inhabıtés en saison sèche. Elles atteignent alors la région de Karal au Sud du Lac et il n'est pas rare d'en troviver quelquesunes à Fort-Lamy. Au Sud de Fort-Lamy, entre Chari et Logone, elles occupent toutes les dépressions boisées ef l'on peut penser qu'à ce nivequ s'effectue un échange de population entre les deux bassins. Sur la rive droite du Chari, le bahr Linia peut être infesté en quelques points. Au Nord de Miltou, cette rive droite, déjà signalée par sa complexité hydrographique est parti- 
culièrement intéressante. En saison des pluies, s'y mêlent les populations de Glossınes du Chari, du bahr Erguig. Telabo et Karma. Les eaux remontent le Batha de Laïri et entraînent ainsı vers le Nord de nombreuses tsé-tsés dans les galeries forestières de ce cours d'equ habituellement dépeuplé.

Dans le Guéra, les mouches s'étendent vers l'Ouest sur quelques kilomètres en empruntant les galeries inondées. A l'Est, depuis Djebren jusqu'à Zakouma, elles atteignent le bahr Korom et ses affluents et remontent une partie du bahr Djourf. Cependant les Glossines ne dépassent jamais la route Abou-Deia Am-Timan.

Partout ailleurs, elles occupent au maximum les galeries forestières qui leur sont offertes par le mouvement des equx.

D'une manière générale, leur extension en saison humide ne dépasse guère les limites données précédemment. A l'intérieur de celles-ci, les Glossines ne restent plus localisées aux abords des gîtes favorables, mais existent partout. Leur répartition devient donc plus diffuse et plus régulière.

\section{Variations depuis le début du siècle.}

Aux varıations annuelles que subit la répartition des Glossines, s'ajoutent celles observées dans le temps depuis le début du siècle. Le recul du temps est assez faıble puisque la première description complète de la distribution des tsé-tsés au Tchad remonte d̀ 1929 (RIQUIER et MALBRANT) et. la deuxième à 1948 (RECEVEUR). Cependant la comparaison des données anciennes et de ces cartes avec celle que nous présentons indique nettement une réduction de l'arre de distribution des Glossines. Nous nous bornerons à citer ces variations et d̀ préciser les lieux où ces retraits sont les plus nets (Carte $n^{0} 7$ ).

Sur le Logone, les tsé-tsés ont régressé depuis Cholem à 20 kilomètres au Nord de Bongor jusqu'à Zymado à 60 kilomètres au Sud de FortFoureau. En avai de Laï, elles arrivaient autrefois à proximité du village, alors qu'aujourd'hui elles sont absentes depuis le confluent PendéLogone occidental.

Au Sud de la route Pala Kelo, MALBRANT indiquait une vaste zone à Glossınes, étendue jusqu'à la frontière camerounaise. Déjà réduite par RECEVEUR, cette zone se limite aujourd'hui à quelques gîtes dispersés.
La dépression du Mandoul signalée comme infestée par RIQUIER en est désormais indemne.

Aux abords du Chari dans la région de FortLamy, le bahr Linia n'esł plus infesté comme cela était signalé autrefois. Les mouches sont absentes des environs de Fort-Lamy. Le Ba-Illi ou Motaya (entre Bongor et Mogroum) qui rejoint la Loumia au Nord n'a pas de tsé-tsés.

Dans la région du Guéra, les Glossines ne dépassent pas Bidjir ou Nord. Elles semblent donc moins septentrionales qu'en 1912 (lieutenant FRANCESCHI). Au Salamat, à l'Est du Guéra la réduction est surtout sensible au niveau de l'Oued Zéreb où elles n'existent plus; elles s'étendent beaucoup moins vers l'Est que ne le signale MALBRANT sur le bahr Djourf.

A l'Est d'Am-Timan, les Glossines occupent une surface plus réduite, la lımıte se déplaçant vers le Sud. Dans la région du Fongoro, la comparaison avec la limite donnée par MALVAL (1927), indiquerait une légère remontée des mouches aux environs de Kademoro.

La réduction de l'aire des tsé-tsés au Tchad depuis les trente dernières années est concomitante, dans les régions à $G$. tachinoides, de la disparition des galeries forestières. Les rives du Logone, de la Loumia, du Motaya-Marba, du Mandoul, de la Tandjilé, de la région supérieure de la Kabia ont été régulièrement et souvent totalement déboisées par l'installation des villages de pêcheurs et l'usage des feux de brousse (de culture ou de chasse) (Carte $n^{\circ} 7$ flèches 1 d̀ 6 ).

Au centre du Tchad, dans le Guéra et le Salamat, les falbles réductions de la zone à G. morsitons submorsitans, au Sud de Mongo, aux niveaux de l'Oued Zered, du bahr Korom et du bahr Djourf (flèches 7 à 10) résultent apparemment de la raréfaction du gibier dans ces endrolts. La cause profonde serait dans un changement des conditions écologiques correspondant à un réchauffement progressif du centre du Tchad!

Il est encore plus difficile de conclure au sujet de la région du Salamat. La réduction marquée par les flèches 11 et 12 est toute théorique car il est difficile d'admettre, même au début du siècle, la présence de mouches tsé-tsés dans la région traversée par le Diokana qui est absolument désertique. Il est fort possible que les limites anciennes ont été établies par des prospections 


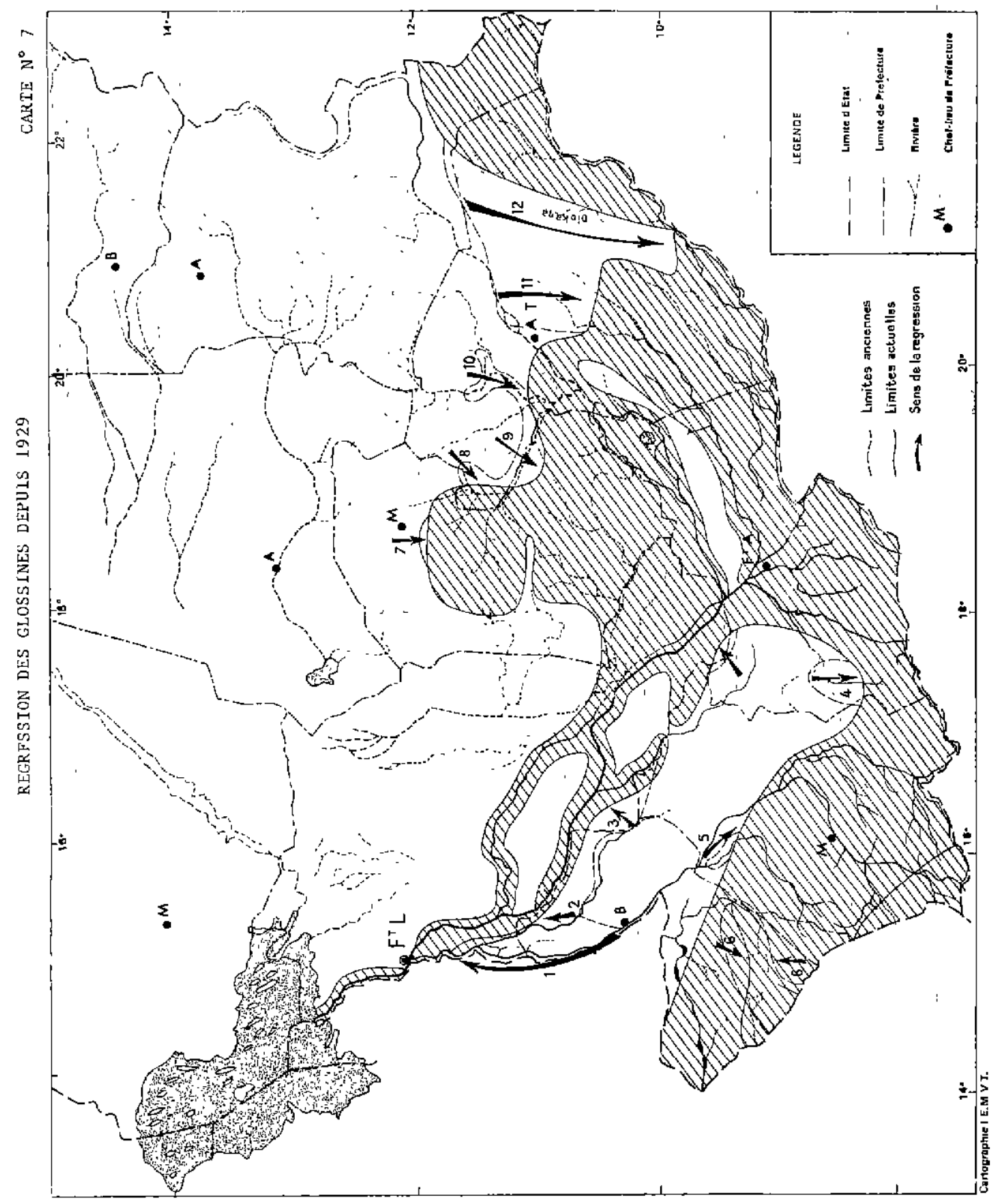


incomplètes en raison du difficile accès de cette région peu hospitalière.

Par contre, il est impossible d'affirmer l'extension des tsé-tsés dans des régions où elles n'étaient pas autrefois signalées et où elles sont très nombreuses actuellement : bassin du Logone occidental et tout le bahr Erguig. Il est probable que ces régions avaient été incomplètement explorées. Tout au plus pourrait-on mentionner, I'on s'en tient aux observations du ROUBAUD (Mission MARTIN-LEB EUF-ROUBAUD, 1906), une légère extension vers le Nord de l'aire de répartition de Glossma fuscipes fuscipes.

\section{b) Distribution de chaque espèce de Glossines.}

Nous avons vu que trois espèces de Glossines se partageaient la partie Sud du Tchad. Les aires de répartition se superposent souvent à l'extrême Sud. Par contre, vers le Nord-Ouest, Glossina tochinoides $W$. se rencontre seule, le Centre et le Nord-Est n'étant occupés que par Gl. morsitans submorsitans $\mathrm{N}$.

Glossina tachinoides W. est la plus septentrionale des espèces tchadiennes puisqu'elle remonte au Nord du $12 \mathrm{e}$ parallèle, le long du Chari jusqu'au lac Tchad. Elle accompagne tous les cours d'eau permanents bordés d'une végétation suffisamment dense pour constituer des galeries forestières.

Dans le bassin du Chari, elle se rencontre : le long du Chari lui-même, sur les affluents de la rive droite : bahr Erguig, bahr Telabo, bahr Karma, bahr Salamat et Bola, bahr Keita, Aouk. Sa limite Nord, du lac Tchad à Djember, correspond ¿̀ la limite générale septentrionale des Glossines. A partir de Djember, elle suit jusqu'à Zakouma la rive droite du Mané-Kondjo et du bahr Bola. Elle devient ensuite Nord-Sud, suivant à l'Est le 20e degré de longitude Est ef se termine à la frontière au niveau du confluent Aoukalé, Aouk. Sur la rive gauche, elle existe le long d'une partie de la Loumia ef le long du Ba-IIIi jusqu'à Nakassao. L'Ouham et ses affluents, ainsi que le bahr Kou et la Sido, portent également des galeries à $G$. tochinoides.

Dans le bassin du Logone, cette espèce se maintient au Sud sur les bords de la Pendé et de la Tandjilé de Bitikine à Tchoa. A l'Ouest, on la retrouve sur la Kabia, de Kordo à ZamréAnday et sur le Mayo-Kebbi, des chutes Gauthiot à Tréné. Elle existe également plus au Sud sur le Mayo Sina, le Mayo Dari, le Mayo Banda Daïne et aux environs de Binder-Nayri. Au Nord, elle se limite à une étroite bande, de Zymado jusqu'qux abords de Fort-Foureau.

Dans le Sud-Ouest du Tchad, sa limite Nord correspond sensiblement à une droite tracée de Bara à Mayo-Lédé et sa limite Sud passe par Dindaga, Gagal, Dafra, Krım-Krim, Moundou, Timbéri, Bédoum, Domou (Cartes 8,13 et générale).

Glossina fuscipes fuscipes $N$. èst la plus mérıdionale et son aire d'extension est très petite. Cantonnée aux galeries forestières denses à végétation de type «soudano-guinéen», elle ne dépasse pas au Nord la région de Krim-Krim ef Kiati. Sur le Logone occidental, elle remonte jusqu'au niveau de Bébedjia à une cinquantaine de kilomètres en aval de Moundou. Sur la Pendé, elle ne dépasse pas le village de Mao. Au Sud de Mandoul on la trouve sur le Niamété ò la latitude de Bodo. Elle existe encore à l'Est de Moïssala, à Bekamba ef aux environs sur la Moula et son affluent le Dou. Sa limite Nord décrit une ligne présentant deux convexités séparées par la dépression du Mandoul. Partout au Sud existe G. fuscipes qui occupe la moindre petite galerie. Cependant c'est dans la partie Ouest de son aire de répartition qu'elle abonde le plus (Cartes 8 , 15 ef générale).

Glossina morsitans submorsitans $N$. Cette espèce est celle qui occupe au Tchad la plus grande superficie. Elle s'étend à toutes les zones de savanes traversées par des cours d'eau intermittents d'où l'eau est absente en saison sèche et dont les formations végétales retiennent les mouches en toute saison. Sa limite Nord et Est correspond depuis Djember à celle donnée pour la répartition générale. A l'Ouest, G. submorsitans ne dépasse pas une ligne très schématiquement rectiligne, tracée de Bitkine à Goré. En réalité, cette limite est plus sinueuse ef présente deux concavités : une entre Melfi et Djember, l'autre entre Chari et Pendé marquée par le Bassin du Mandoul (Cartes 8, 14 ef générale).

La carte no 9 montre les rapports qui existent entre les aires de répartition des Glossines au Tchad ef celles des Etats voisins de l'Afrique Centrale. Seul, le Nord Cameroun, incomplètement prospecté, présente encore quelques imprécisions. 


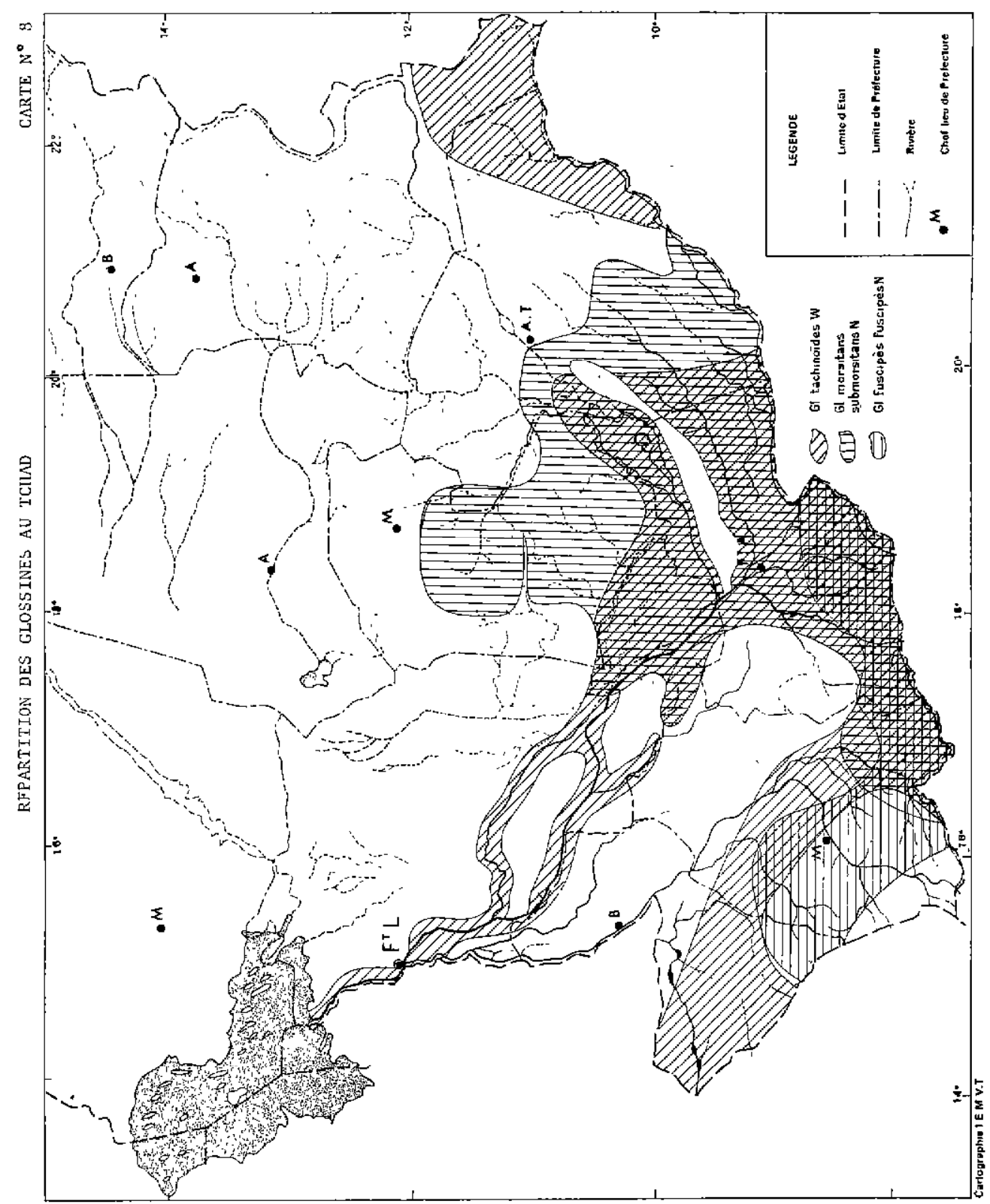




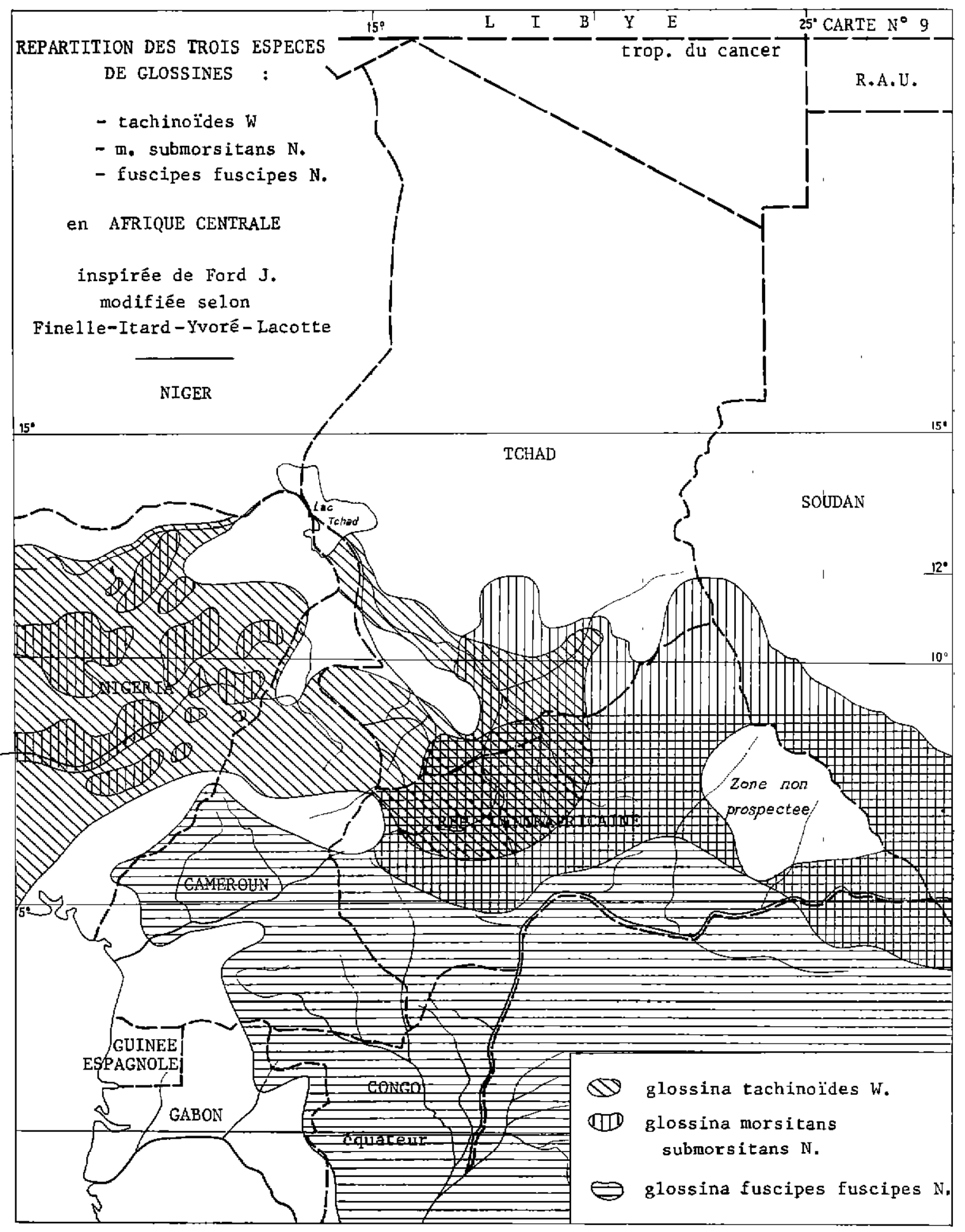




\section{I. - CONDITIONS ÉCOLOGIQUES GÉNÉRALES}

\section{Généralités sur le Tchad (Carte no 10 ).}

La République du Tchad, d'une superficie totale de 1.284.000 kilomètres carrés, est comprise entre les $8^{\mathrm{e}}$ et $24^{\circ}$ degrés de latitude Nord et entre les $14 \mathrm{e}$ et $24 \mathrm{e}$ degrés de longitude Est. L'ensemble du pays est remarquablement plat et d'une altitude moyenne de $300 \mathrm{~m}$. Quelques massifs montagneux s'y rencontrent cependant : au Nord, le Massif du Tibesti avec son point culminant de $3.400 \mathrm{~m}$ (Emi-Koussi), d̀ l'Est, le massif de l'Ennedi dont certains sommets atteignent près de $1.400 \mathrm{~m}$ et qui se prolonge vers le Sud le long de la frontière du Soudan par quelques formations de faible altitude, au Centre, les massifs du Guéra $(1.800 \mathrm{~m})$ et de l'Abou-Telfan. Au Sud, un seuil peu élevé sépare les bassins du Chari et du Congo, en bordure de la frontière avec la République Centrafricaine.

Le résecu hydrographique tout entıer est situé dans la moitié Sud du territoire et son tracé résulte du relief indiqué.

Partant des régions montagneuses de l'Est en évitant les zones élevées du Guéra, du Sud en se dirigeant vers le Nord, les cours d'eau se déversent dans le Charl et le Logone qui se jettent dans la cuvette du lac Tchad dont le nivequ n'est que de $250 \mathrm{~m}$. Les deux grands fleuves et leurs principaux affluents occupant ainsi le Sud-Sud-Est, le Sud et le Sud-Ouest du Tchad ont de l'eau en permanence; l'Est du territoire n'étant parcouru que par des Ouaddi, à sec durant la plus grande partie de l'année.

Le climat tchadien est marqué par l'alternance d'une saison sèche et d'une saison des pluies nettement différenciées, mais dont les durées varient selon la latitude. La Carte des isohyètes (Carte no 11) établie sur des résultats recueillis pendant 10 et 30 ans, montre l'importance des précipitations. La température est dans l'ensemble élevée toute l'année ; à FortLamy par exemple, la moyenne annuelle est de $28^{\circ} \mathrm{C}$ avec des écarts de $8^{\circ}$. L'humidité est très variable allant de 5 p. 100 en saison sèche à 98 et 100 p. 100 en saison des pluies. L'examen des durées relatives des saisons sèches et pluvieuses permet de distinguer au Tchad quatre zones climatiques correspondant à des types de végétation différents et qui sont du Nord au Sud :

1) une zone de climat saharien, située approximativement au Nord du $15^{\circ} 30^{\circ}$ Nord, où les chutes de pluie sont constamment inférieures d̀ $300 \mathrm{~mm}$;

2) une zone de climat sahélo-saharien, comprise entre les parallèles $13^{\mathrm{e}}$ et $15^{\mathrm{e}} 30^{\prime}$ dont les chutes de pluie varient de 300 à $500 \mathrm{~mm}$;

3) une zone sahélo-soudanienne, grossièrement limitée par les $9 \mathrm{e}$ ef $13^{\mathrm{e}}$ parallèles et où la pluviométrie est comprise entre 500 ef $1.100 \mathrm{~mm}$. Le paysage végétal est représenté par des forêts claires et des savanes boisées à Légumineuses où dominent les formes xérophiles. Les galeries forestières du Logone et du Chari modifient le milieu. Les zones sahéliennes constituent la zone d'élevage par excellence, principalement entre les $12^{\mathrm{e}}$ et $14^{\mathrm{e}}$ parallèles ;

4) une zone soudano-guinéenne, au Sud du ge parallèle où la pluviométrie est dans l'ensemble supérieure à $1.000 \mathrm{~mm}$. C'est une région agricole, la plus peuplée du territoire.

\section{Caractères généraux des zones à Glossines.}

Les tsé-tsés ne dépassent pas au Nord le $12^{\mathrm{e}} \mathrm{pa-}$ ralièle, sauf le long du Chari en aval de FortLamy. Leur aire de répartition esten conséquence entièrement située dans les zones sahélo-soudanienne et soudano-guinéenne (Carte no 12).

Mis à part le bassin du bas-Chari qui détermine des conditions écologiques favorables en conservant d'importantes galeries forestières ef l'extrême Nord-Est du Guéra, les Glossines occupent une surface entièrement située au Sud de l'isohyète de $700 \mathrm{~mm}$ et dont la presque totalité est comprise dans celui de $900 \mathrm{~mm}$.

La partie de la zone sahélo-soudanienne occupée par les tsé-tsés est une savane arborée plate ou dominent les espèces végétales : Butyrospermum parkii Kotschy, Khayo senegalensis (Desv.) A. Juss., Daniellia oliverl (Rolfe) Hutch, et Dalz. Relevée dans la région du Guéra par quelques formations montagneuses entre Dagela et Mongo, elle est traversée par de nombreux cours d'eau dont la majorité est à sec pendant la saison sèche. Ces bahrs intermittents qui ne coulent qu'en saison des pluies tracent dans la savane des couloirs herbeux bordés par endroits de Mitragyna inermis (Willd.) O. Ktze. Ils constituent des 


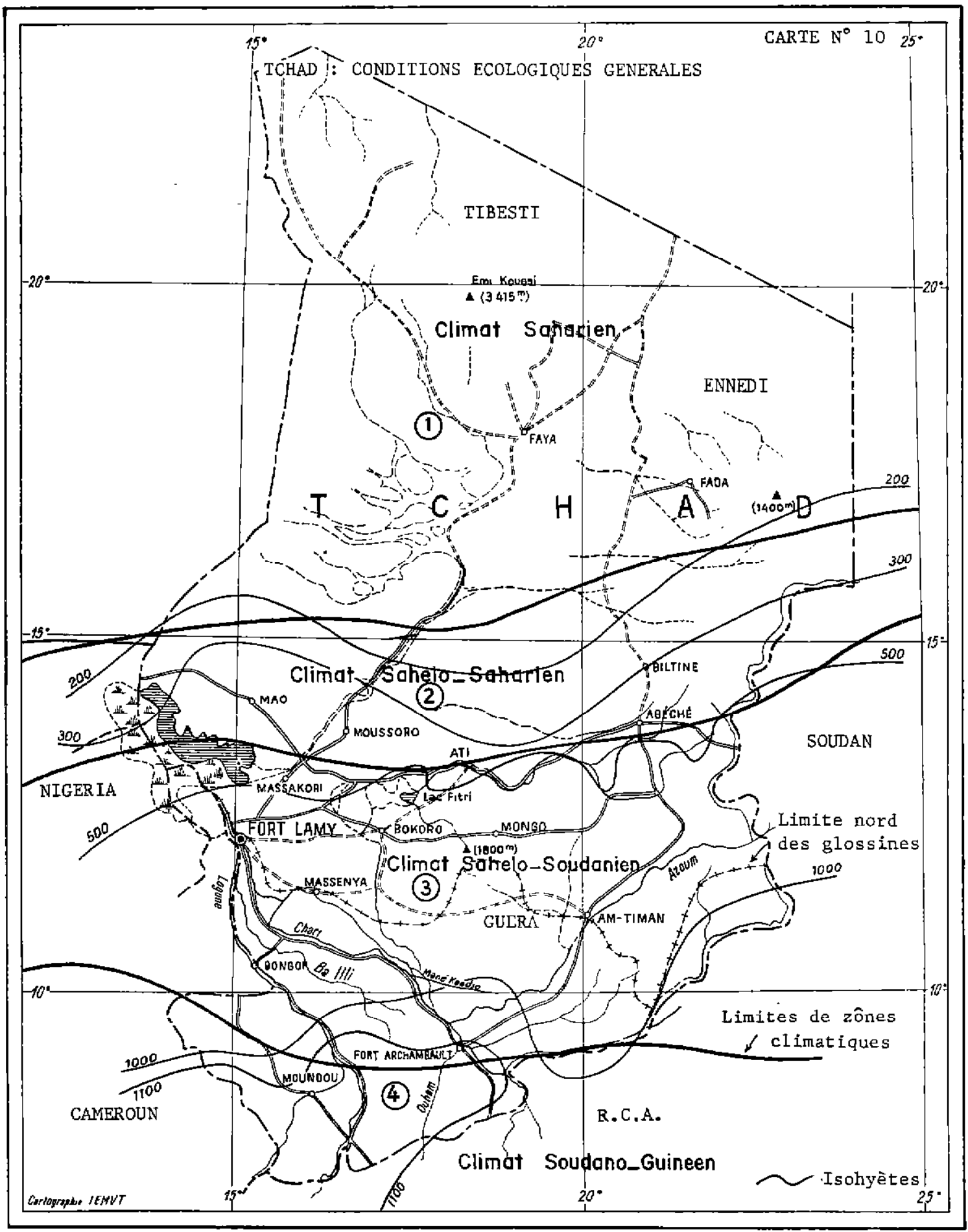




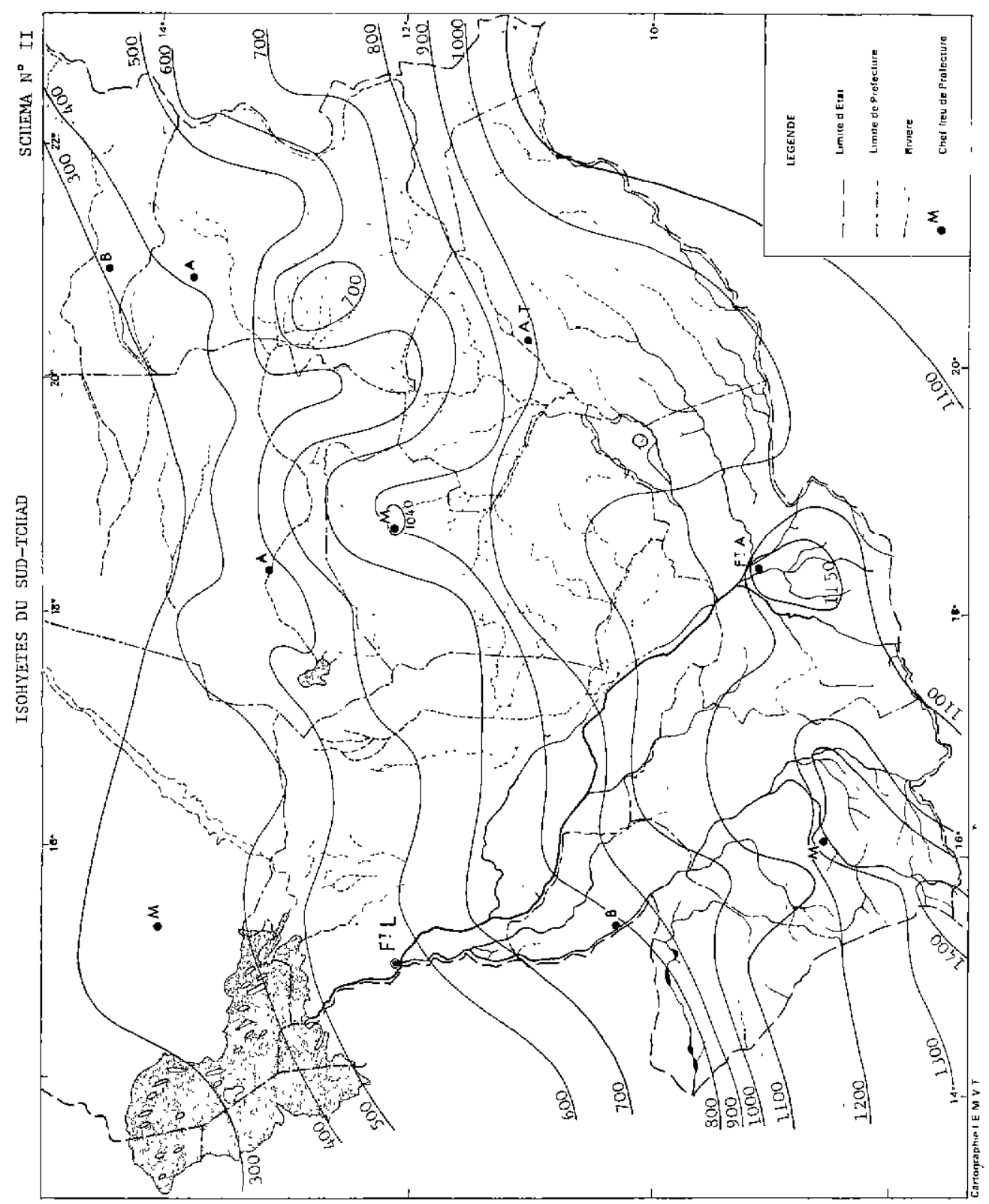




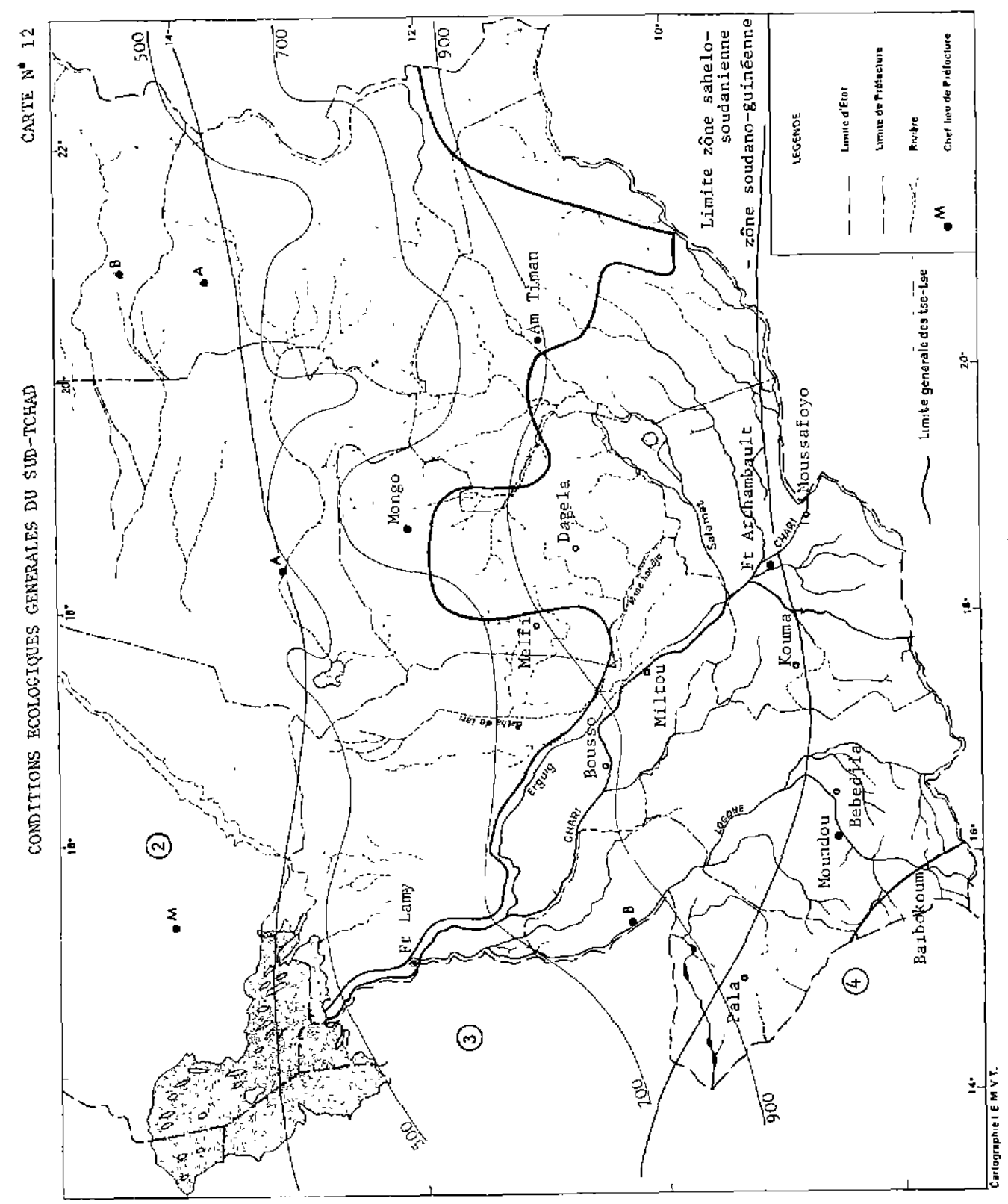


lieux de concentration de Gl. morsitans bsumorsitans $N$. qui se répand facilement dans la savane boisée sèche des environs. Au centre de cette zone, le Mané-Kondjo est le bahr permanent le plus septentrional. II se prolonge vers l'Ouest par une zone d'inondation où convergent après les pluies le Batha de Laïri ef le bahr Erguig. Cette zone inondable, située au Nord de Miltou, est constituée par de nombreux cours d'ecu très sinueux comprenant un lit central et de nombreux bras et dérivations en culs-de-sac. Lorsque les bords du lit sont bien marqués, la végétation ripicole est dense. Elle est constıtuée par des arbres : Anogeissus leiocorpus (DC.) Guill, et Perr., Tamorindus indica L. : Acocia ataxacantha DC., Acacia sieberiana DC.; par des lianes: Merremia hederocea (Burm. f.) Hall. et Cardiospermum halicacabum L. et par des plantes basses : Borreria fillfolia (Schum et Thonn.) K. Schum. Aeschynomena afraspera J. Léonard, Aeschynomene indica L., Melochia corchorı folia L., Eragrostis pilosa (L.), P. de Beauv., Cassia mimosoides L., Hyptis specigera Lam.

Ces formations constituent des gîtes parfaits pour Glossina tachinoides W. qui s'y trouve en abondance. Les Glossines peuvent trouver des gîtes temporaires lors des inondations le long des mares, des défluents où la végétation est disséminée.

L'humidité est alors suffisante pour permettre les déplacements des mouches jusqu'à ces abris. Aux environs de Miltou, dans la deuxième quinzaine d'octobre, à l'époque où les eaux s'étendent au maximum, on a noté (GILLET) les humidités ef températures suivantes :
- à 6 h, 96,6 p. 100 d'humidité avec $21,5^{\circ} \mathrm{C}$.

- à 12 h. 54,4 p. 100 d'humidité avec $32,4^{\circ} \mathrm{C}$.

- à 18 h, 85 p. 100 d'humidité avec $25,6^{\circ} \mathrm{C}$.

Nulle part ailleurs, à I'intérieur, la végétation de savane n'est favorable au maintien des tsé-tsés.

Le tableau $n^{\circ} 2$ résume les températures ef les humidités observées en différents points de la zone sahélo-soudanienne. Toute la zone soudanoguinéenne occupant le Sud du Tehad reçoit des chutes de pluies comprises entre $1.000 \mathrm{~mm}$ et $1.400 \mathrm{~mm}$ (1.420 à Baïbokoum) qui s'étalent sur sept mois de l'année. Les cours d'eau relativement peu nombreux sont permanents et bien individualisés. Ils sont bordés d'une végétation luxuriante formant des galeries forestières assez denses où se trouve en abondance Glossina fuscipes fuscipes $N$. qui recherche l'ombre et une humidité élevée. Dans la partie Sud de la dépression du Mandoul, ces galeries sont constituées par les espèces végétales suivantes : Vitex doniana Sweet, Syzygium guineense (Willd) DC., Anthocleista schweinfurth Gilg, Ficus capensis Thumb. Dans la région de Moussafoyo, deux espèces d'arbres domınent sur les bords du Chari : Tamarindus indica $\mathrm{L}$. et Diospyros mespiliformis Hochst., sous lesquels croissent un arbuste Allophylus africanus P. de Beauv. et une liane Hippocrateo ofricono (Willd.) Loes. L'ensemble constitue une galerie forestière où gîte $G$. tachinoides. Le long des petits cours d'eau intérieurs, on retrouve Syzygium guineense (Willd.) DC. mêlé aux autres espèces; vers l'intérieur, s'étale une forêt sèche à Anogeissus leiocarpus (DC.) Guill. et Perr. puis la savane. Glossina marsitans sub-

TABLEAU NOII

Zone Sazelo-Soudanzenne

\begin{tabular}{|l|c|c|c|c|c|c|}
\hline \multirow{2}{*}{ Localités } & \multicolumn{3}{|c|}{ Température 00} & \multicolumn{3}{|c|}{$\begin{array}{c}\text { Pourcentage } \\
\text { humidité }\end{array}$} \\
\hline \multirow{3}{*}{ Fort-Lamy } & minimum & meximum & moyenne & minimum & maximum & moyenne \\
\cline { 2 - 7 } Mongo & 20,2 & 35,6 & 27,9 & 18 & 98 & 58 \\
Am-Timen & 22,5 & 35,4 & 29 & 7 & 94 & 50 \\
Bougso & 18,8 & 35 & 26,9 & 12 & 98 & 55 \\
Ft-Archambault & 20,8 & 35,2 & 28 & 17 & 96 & 56 \\
\hline
\end{tabular}


morsitons N. peut s'y rencontrer par endrolt. Quelques températures et humidités de la zone soudano-guinéenne sont données dans le tableau $n^{\circ} 3$.

Des trois espèces de Glossines présentes au Tchad, G. fuscipes est la seule dont l'aire d'extension est pratiquement toute comprise dans la zone soudano-guinéenne. Les autres espèces se rencontrent dans les deux zones climatiques, $G$. submorsitons ayant son arre de répartition maximum dans la zone sahélo-soudanienne. Par ailleurs, $G$. submorsitons s'oppose à $G$. tachinordes et à $G$. fuscipes par le fait qu'elle s'adapte facilement à la savane sèche alors que les deux autres recherchent l'humidité et sont tributaires du réseau hydrographique.

\section{Facteurs écologiques déterminant la répartition des Glossines.}

La présence des mouches tsé-tsés dans une région dépend de conditions géographiques (climat, hydrographie) favorables, d'une végétation constituant des zones ombragées et de l'abondance de sources de nourriture.

Ces éléments sont étroitement liés les uns aux autres; le climat, le réseau hydrographique déterminent la végétation et les conditions de vie humaine et animale, la végétation madifie le micro-climat et crée des étendues où les animaux trouvent pâturages et couverts protecteurs.

La température et I'humidité sont les conditions climatiques dont l'influence est prépondérante sur la présence des Glossines. Elles doivent être maintenues dans les limites relativement constantes et variables selon les espèces. Le réseau hydrographıque détermine une végétation ripicole qui conserve l'humidité et la tem- pérature aux conditions exıgées. Celles-ci sont en général différentes de celles du milieu environnant.

L'Homme, les animaux domestiques ef la faune sauvage constituent les sources de nourriture des tsé-tsés. Chaque espèce de Glossines montre des préférences dans le choix de ses hôtes; G. fuscipes semble préférer l'Homme, G. submorsitans recherche les gros mammifères alors que $G$. tachinoides est indifférente, se nourrissant aussi bien sur l'Homme que sur les animaux.

Les éléments : climat-hydrographie, végétation et sources de nourriture doivent être réunis pour justıfier la présence des Glossines dans une région. L'absence ou l'incompatibilité de l'un d'entre eux suffit à empêcher le maintien des mouches.

\section{Répartıtion de Glossina tachinoides W.}

Le cours du bas-Chari, situé entre les isohyètes de 500 et $700 \mathrm{~mm}$, est bordé de galeries forestières importantes qui maintiennent une température et une humidité favorables à la présence de G. tachinaldes. La masse d'eau constituée par le fleuve détermine une source permanente d'humidité pour la région qu'il traverse.

Mise ḋ part cette bande longue d'environ 200 kilomètres, $G$. tachinoides a son aire d'extension située dans une zone où les précipitations sont constamment supérieures à $700 \mathrm{~mm}$. Sa présence est entièrement liée aux galeries forestières qui bordent le réseau hydrographique permanent ; elle exige une humidité importante et supporte difficilement la sécherésse. En conséquence, elle s'éloigne peu de ses gîtes sauf aux heures fraîches de la journée en saison sèche et pendant la période des inondations.

TABLEAJ WOIII

Zone S oudeno-Guinéemne

\begin{tabular}{|c|c|c|c|c|c|c|}
\hline \multirow[t]{2}{*}{ Localités } & \multicolumn{3}{|c|}{ Tempérstures ${ }^{\circ} \mathrm{C}$. } & \multicolumn{3}{|c|}{$\begin{array}{l}\text { Pourcentage } \\
\text { humidité }\end{array}$} \\
\hline & minimum & maximum & mogenne & mintmum & maximum & noyenne \\
\hline Pala & 20,8 & 35,5 & 27 & 15 & 91 & 53 \\
\hline Moundou & 20,2 & 33,9 & 27 & 17 & 97 & 57 \\
\hline Bébedjia & 19.7 & 34,8 & 27,2 & - & - & 68 \\
\hline
\end{tabular}


Elle se répand alors à l'intérieur et trauve des gîtes temporaires; mais elle ne s'éloigne guère de plus de 2 kilomètres de son point de départ par ses propres moyens.

Les températures enregistrées dans les gîtes au mois d'avril, en pleine saison sèche et chaude, varient de $20^{\circ} \mathrm{C}$ à $37^{\circ} \mathrm{C}$ au cours de 24 heures. Le maximum est atteint vers 14 heures et le minimum à 4 heures. Au même lieu l'humidité passe de 31 p. 100 d̀ 12 heures, à 75 p. 100 entre 3 et 6 heures. La période d'activité se situe le matin et en fin d'après-midi quand la température est vosine de $30^{\circ} \mathrm{C}$ et l'humidité d'environ 40 p. 100.

Les galeries forestières hébergent $G$. tachinordes sont formées d'espèces végétales constituaht des tonnelles ou des voutes dominant un sous-bois généralement dégagé. Elles présentent une certaine constance dans leur constitution et en général deux zones de végétatıon peuvent être reconnues à partir du lit mıneur du fleuve: schéma 1.

1) une zone inondable formée de buissons riverains et de taillis ombragés où dominent Mimosa pigra L., Morelia senegalensis A. Rich. ex DC., Paullinia pinnata L. ou Cordia rothi Roem. et Schult. et Oncoba spinosa Forsk. selon les lieux:

2) une zone de bordure située entre la précédente et la savane, composée de Tamarindus indica L., Acacia sieberiana DC., Acacia ataxacantha DC., Drospyros mespiliformis Hochst., Ziziphys abyssinica Hochst. ex A. Rich.

Les étendues de ces différentes zones sont variables ; parfois, lorsque les rives sont relevées, la zone inondable n'existe pas ef le lit mineur est directement bordé par la zone de bordure. Le type général se rencontre en aval de Fort-Lamy, à Riggil et à Dro ainsi qu'aux environs de Ba-IIlı.

Les bords des fleuves abritent le plus souvent une fqune riche et variée qui est pour les tsé-tsés une source inépuisable de nourriture; phacochères, hippopotames, crocodiles et antilopes sont le plus souvent sollicités. D'autre parti la population humaine y est également abondante: villages de pêcheurs principalement. On constate très fréquemment que les gîtes où les Glossines abondent le plus sont ceux situés à proximité de ces villages. G. tochinoides semble ainsi rechercher la présence de l'Homme qui apparaît comme un hôte préférentiel. Ce contact permanent entre l'Homme et la mouche contribue à maintenir quelques fayers de Maladie du sommeil : bords du Bahr Erguig, environs du Ba-lili, région Nord de Miltou. De plus, lorsque les troupeaux viennent s'abreuver aux fleuves en saison sèche, lorsque les points d'eau de l'intérieur ont disparu, ils peuvent contracter la trypanosomiase.

Ainsi, G. tochinordes dont la présence est intimement liée à l'eau, à des couverts denses mais à sous-bois dégagés où elle trouve une nourriture abondante, ne se rencontrera qu'à proximité des cours d'eau à débit permanent bordés de galeries forestières. On ne la trouvera pas à I'Est du Tchad auprès des Oueds intermittents, ni à l'Ouest dans les grandes savanes qui séparent les rivières. A l'extrême Sud-Ouest où la végétation est rare ou trop dense pour elle, elle laisse la place à $G$. fuscipes (Carte no 13).

Répartition de Glossina morsitans submorsitans $N$.

L'aire de répartition de $G$. submorsitans est tout entière située dans la zone où les pluies excèdent $700 \mathrm{~mm}$; mais à l'opposé de G. tachinoides, cette espèce semble éviter les régions dont le climat est modifié par des galeries forestières qui gardent une humidıté élevée. Elle préfère les régions plus sèches, ce qui explique sa présence dans l'Est du Tchad, dans les savanes boisées où les cours d'eau sont à sec pendant près de 7 mois de l'année et conservent malgré tout dans les zones forestières le peu d'humidité indispensable d̀ sa survie. Plus adaptable que les autres espèces à la sécheresse, elle se trouvera néanmoins dispersée dans la savane, dans les lieux ensoleillés non abrités.

G. m. submorsitons prend sa nourriture exclusivement sur les onimaux : troupeaux nomades et surtout gros gibier. On peut dire que les déplacements du gibier conditionnent ceux des tsétsés. En pleine scison sèche, celui-ci se groupe auprès des rares points d'eau abrités où G. submorsitans se rencontre alors en très grande abondance. En conséquence, elle se trouvera surtout dans les régions inhabitées par l'Homme. L'installation de nouveaux villages, la mise en culture de régions riveraines, les feux de brousse détruisent les galeries forestières ou les savanes boisées de l'intérieur et contribuent à chasser le gıbıer et les mouches. Dès que la population humaine augmente suffisamment pour perturber la faune, le gibier et les tsé-tsés disparaıssent. 
SCHEMA $\mathrm{N}^{\circ} \mathrm{I}$

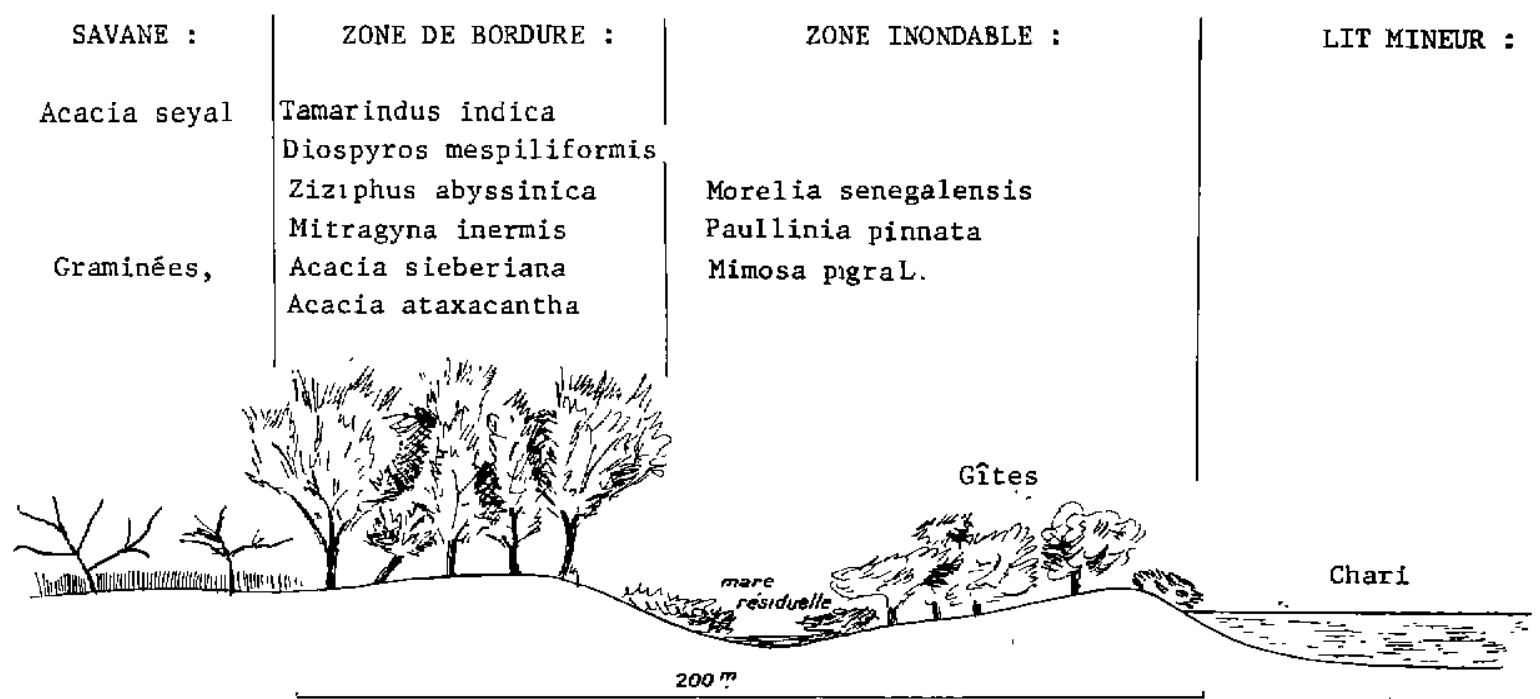

Galerie forestière à G.tachinoides. Schêma gênéral typique : environs de Ba-Illi

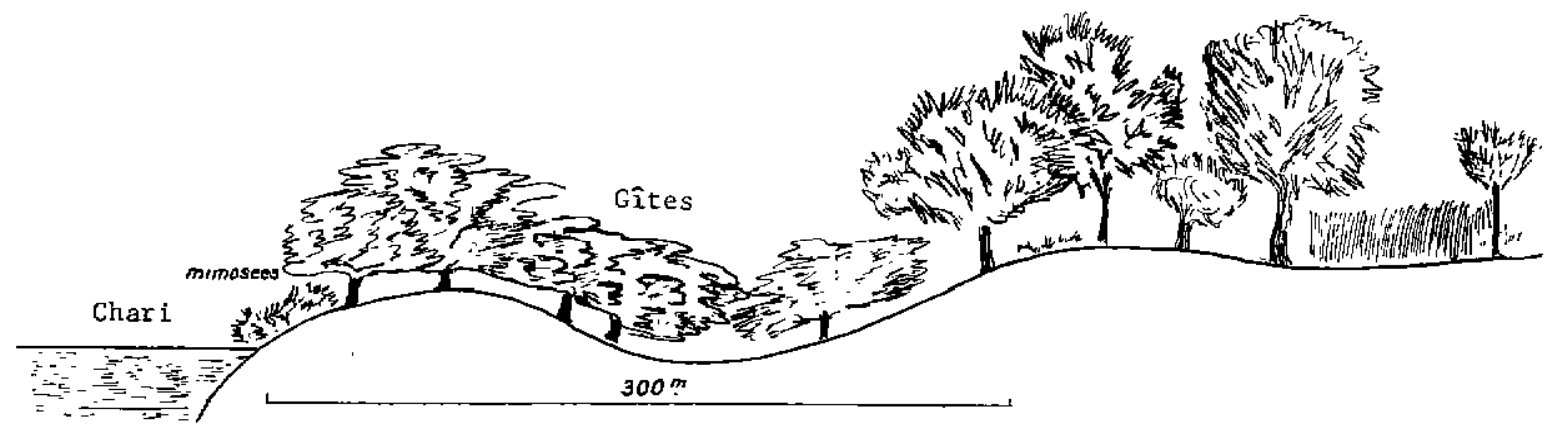

Gîtes de Dro (G.tachinoides), rive droite.

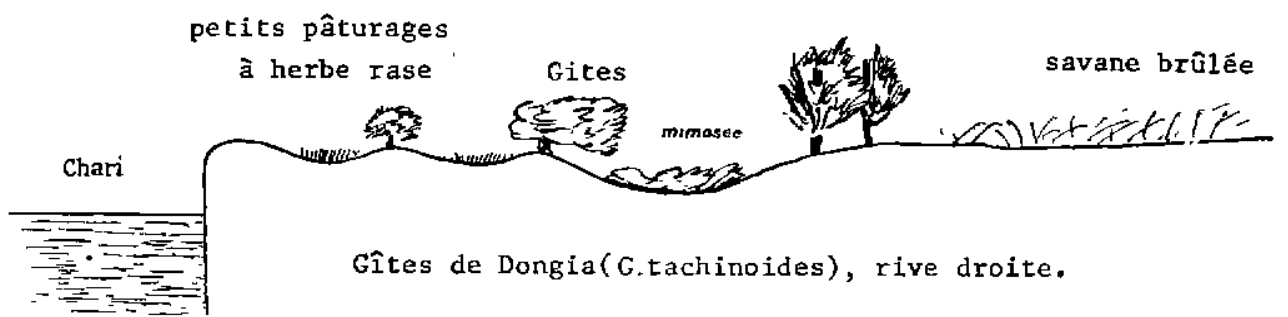




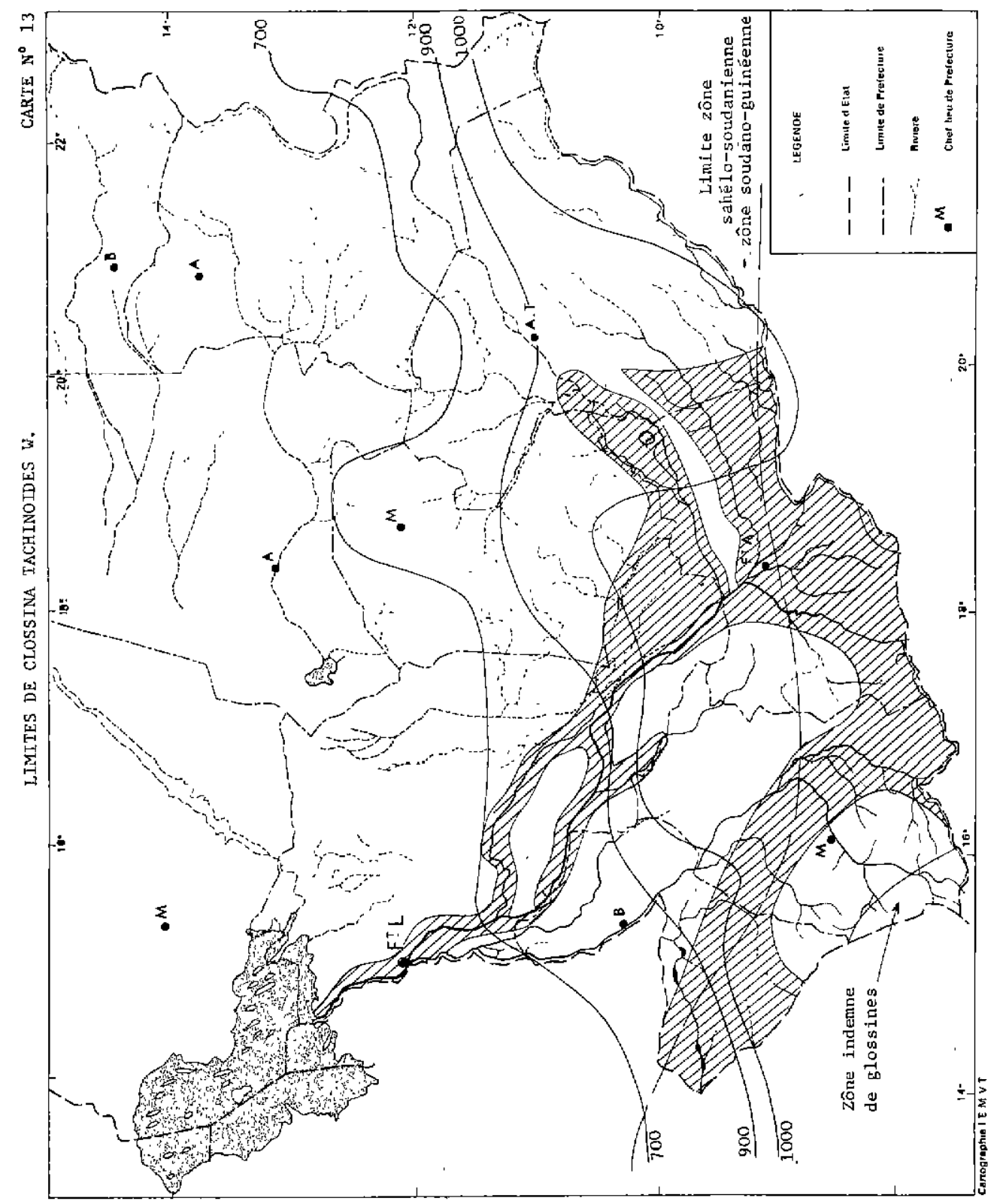


La réunion de toutes ces conditions explique sa distribution au Tchad. Vers le Nord, elle ne dépasse pas le $12^{\mathbf{e}}$ parallèle au Nord duquel la végétation est rare et où l'hygrométrie est. trop faible pour conserver le gibier et abriter les mouches. A l'Est d'Am-Timan, la vallée du Diokana, aride et désertique, ne peut en héberger. A l'Ouest, elle ne dépasse pas une ligne tracée schématiquement de Bitkine à Goré au-delà de laquelle sont installés de nombreux viliages et où le gibier est rare. Vers le Sud-Ouest, elle n'existe pas où la pluviométrie dépasse $1.300 \mathrm{~mm}$. Le long des cours d'eau importants (bahr Salamat, bahr Aouk), elle peut se rencontrer en compagnie de $G$. tachinoides qui reste étroitement cantonnée à leurs rives.

G. submorsitans se limite donc au Centre du Tchad aux savanes boisées riches en gibier, traversées par des cours d'eau à régime temporaire et où la pluviométrie est comprise entre 700 et $1.300 \mathrm{~mm}$ (Carte no 14). Il existe au Muséum National d'Histoire Naturelle de Paris un lot de $G$. submorsitons provenant de la collection FLEUTIAUX 1905, ef portant pour origine lac Tchad. L'imprécision du lieu ne permet pas d'affirmer qu'il y a eu des Glossines dans cette région où personne n'en a jamais trouvé. Elles existent au Sud-Est à plus de 300 kilomètres du lac.

\section{Répartition de Glossina fuscipes fuscipes $\mathrm{N}$. (Carte no 15).}

L'aire de répartition de cette espèce est au Tchad très réduite et presque entièrement située dans la zone soudano-guinéenne et comprise dans les régions où les pluies dépassent $1.100 \mathrm{~mm}$.

Ses exigences en humidité font qu'elle ne vit bien que dans les galeries forestières denses, fortement ombragées et où l'humidité reste toujours très élevée.

La composition de ces galeries est différente de celles où vit $G$. tachinoides ; elles sont formées de plantes de régions guinéennes, le plus sou- vent entremêlées et ne ménageant pas de sousbois dégagés. Dans le Sud du Tchad, I'aspect de la végétation ripicole suffit à indiquer l'espèce qui y vit.

Comme $G$. tachinoides, $G$. fuscipes se rencontre au voisinage de I'Homme qui constitue sa principale source de nourriture. Le Sud-Ouest du Tchad est la région la plus peuplée du pays et celle où cette espèce abonde. Les rapports étroits qui existent entre elle et l'Homme expliquent les nombreux cas de Maladie du sommeil que I'on enregistre chaque année, aux environs de Moundou notamment.

Parmi les facteurs agissant naturellement sur la distribution des Glossines, deux d'entre eux, végétation ef sources de nourriture, apparassent donc comme décisifs. Cependant, ils peuvent être profondément modifiés par l'action de l'Homme qui intervient alors comme un facteur secondaire toin d'être négligeable. En effet, devant les feux de brousse et les défrichements traditıonnels nécessaires à l'installation de nouveaux villages et de nouveaux champs, devant la création de routes ef l'agrandissement des villes, la végétation recule constamment. La chasse traditionnelle et moderne, plus meurtrière encore, atteint fortement la faune sauvage et réduit de plus en plus son aire de dispersion. Ainsi, les conditions de vie nécessaires aux Glossines sont naturellement modifiées et celles-ci reculent lentement et régulièrement devant la civilisation.

L'action raisonnée sur la végétation, la destruction du gibier, jointes à l'emploi d'insecticides puissants pourraient être utilisés au Tchad comme cela a été fait en Afrique de l'Est pour combattre rapidement et efficacement l'indésirable mouche tsé-tsé à laquelle I'Homme et les animaux domestiques paient encore un trop lourd tribut.

Le schéma no II tente de mettre en évidence les rapports entre les différents éléments conditionnant la présence des mouches tsé-tsés. 
LIMITES DE GLOSSINA MORSITANS SUBMORSITANS N;

CARTE N* 14

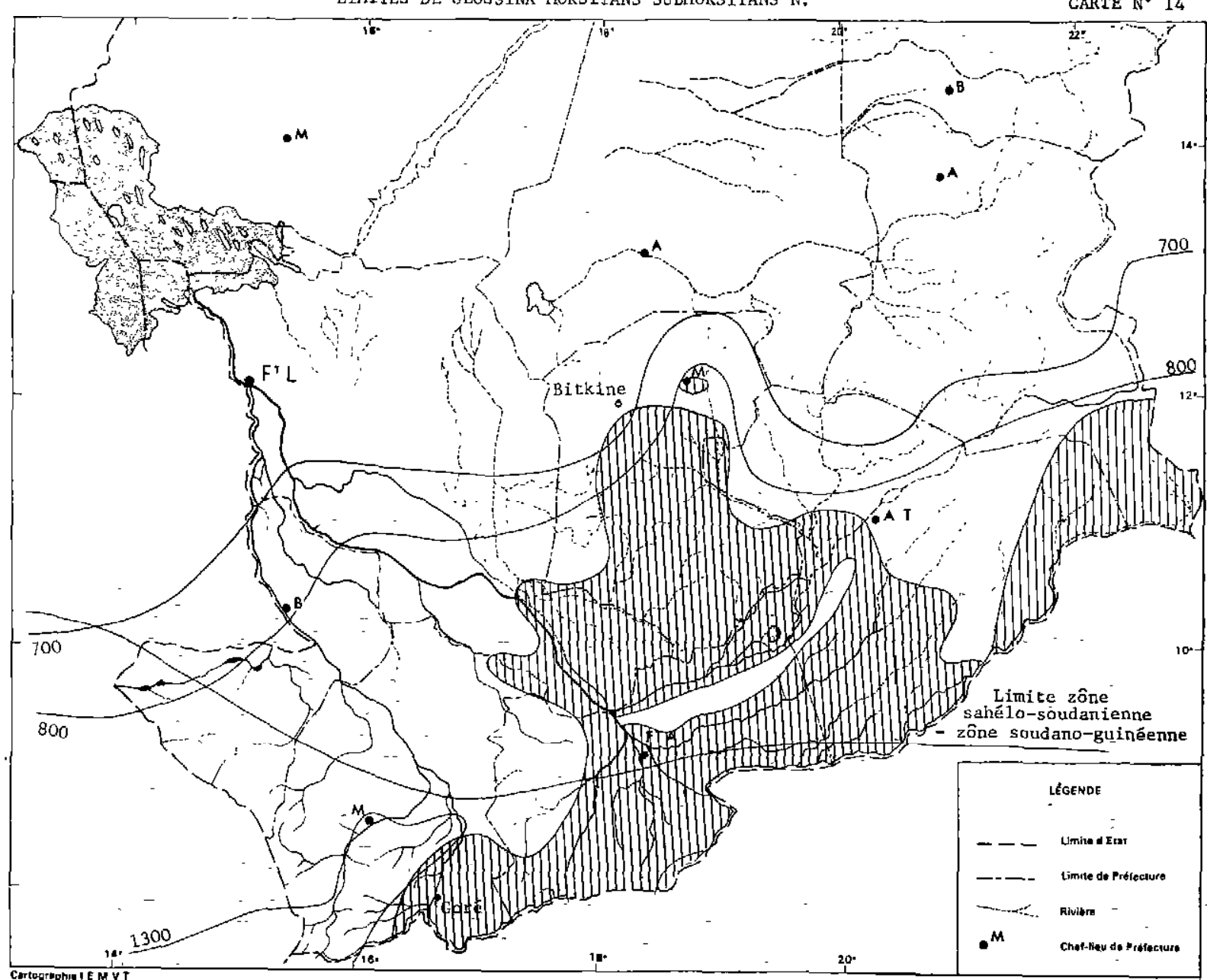


LIMITES DE GLOSSINA FUSCIPES FUSCIPES $N$ CARTE N ${ }^{\circ} 15$

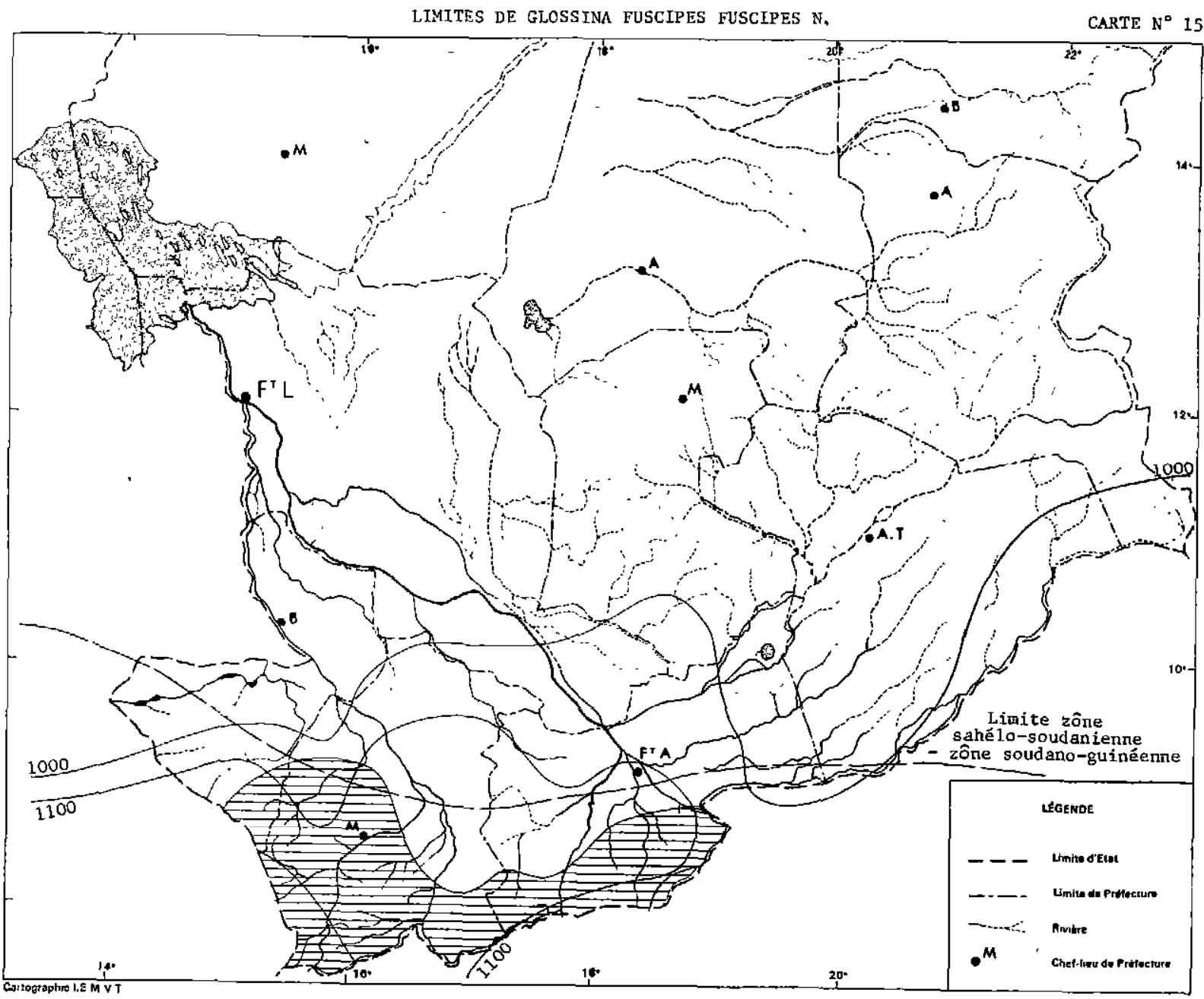


CARTES AU/200.000 COUVRANT LES 2ONES A GLOSSINES

CARTE $N^{\circ} 16$

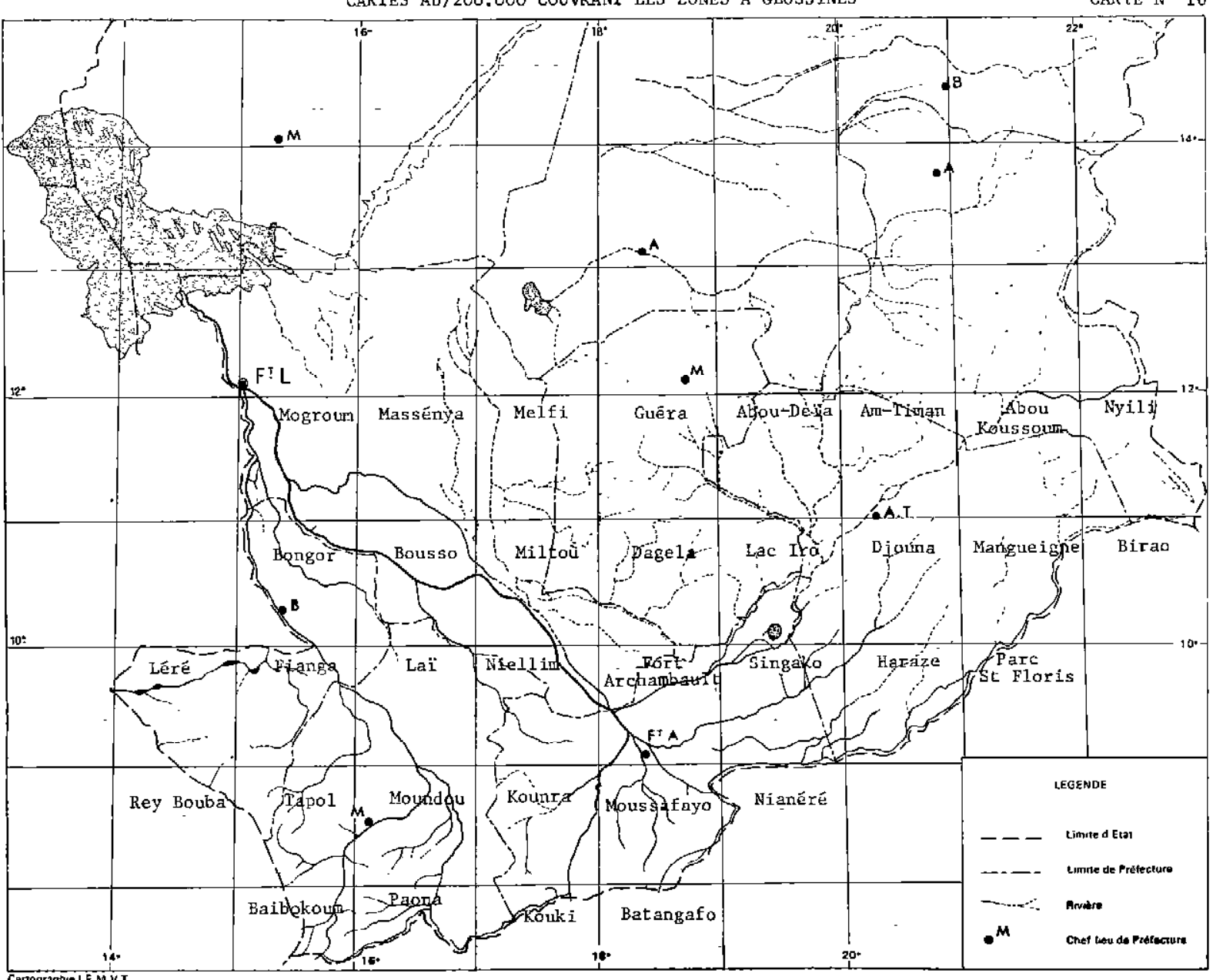


SCHEMA $\mathrm{N}^{\circ} 2$ MONTRANT LES RAPPORTS ENTRE LES DIFFERENTS ELEMENTS AGISSANT SUR LA REPARTITION DES MOUCHES TSETSES

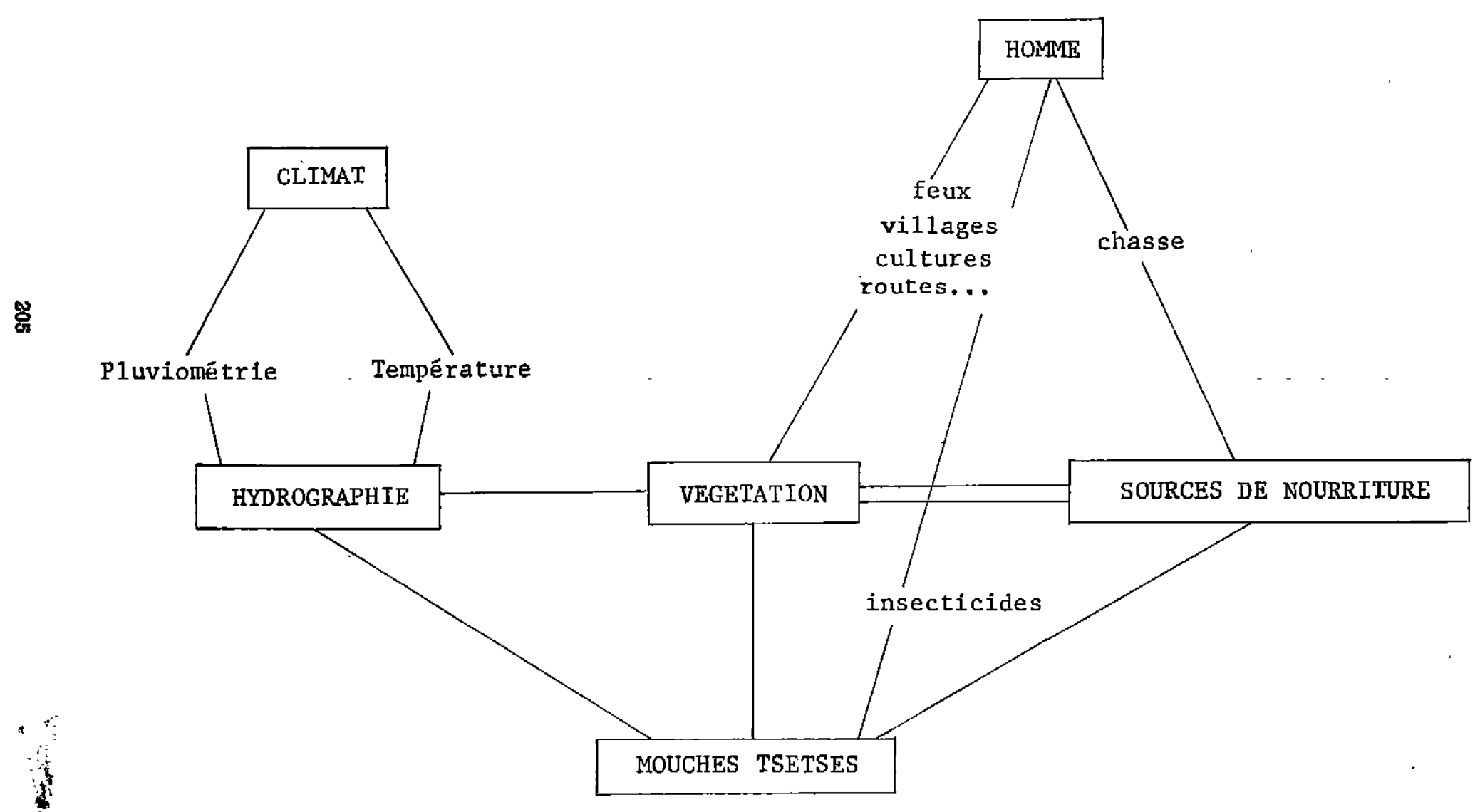




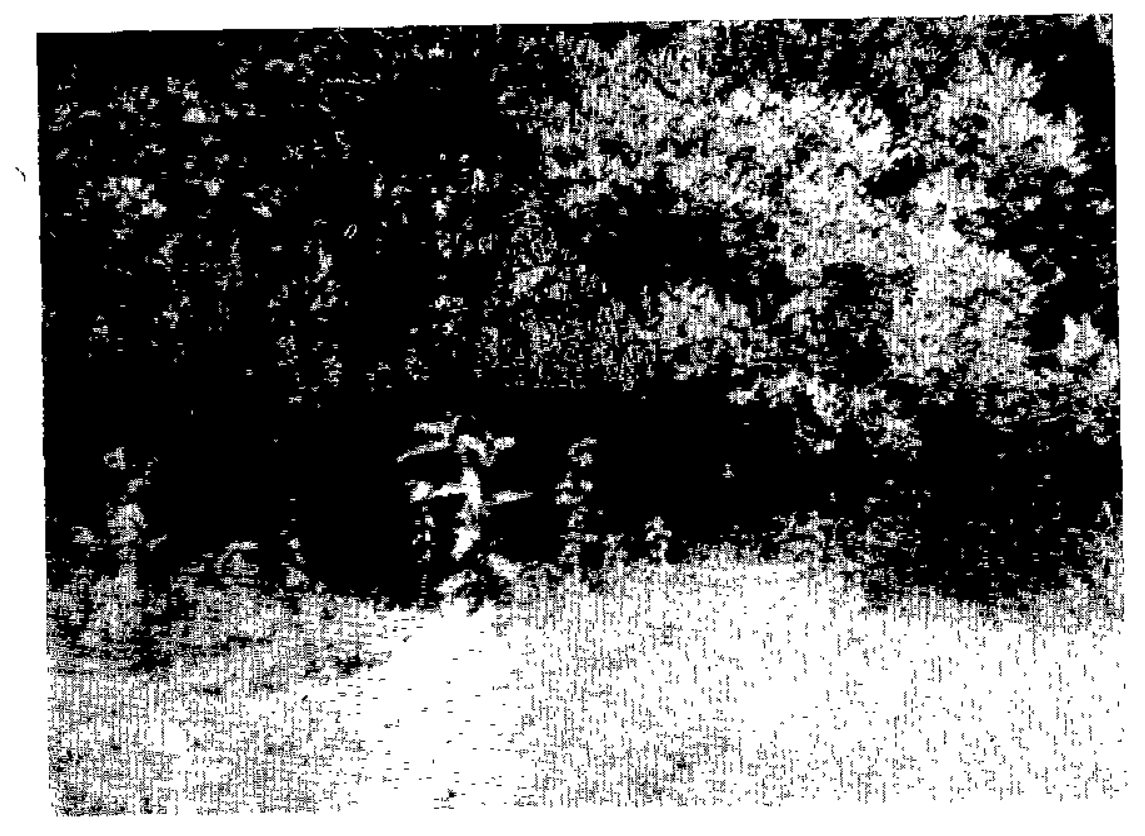

No 1. - Gîtes à Gl, tochinoides W. - Riggil (Bas-Chari).

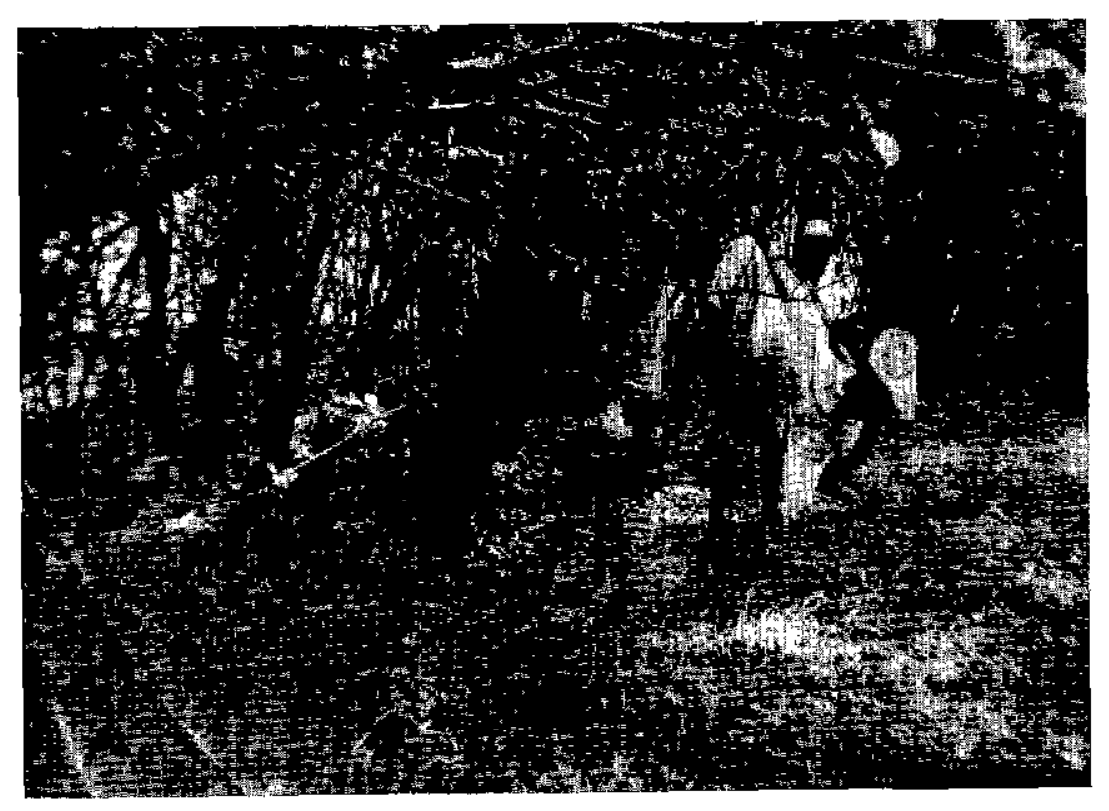

No 2. -. Gîtes à Gl. tachinordes W. - Bahr Erguig. 


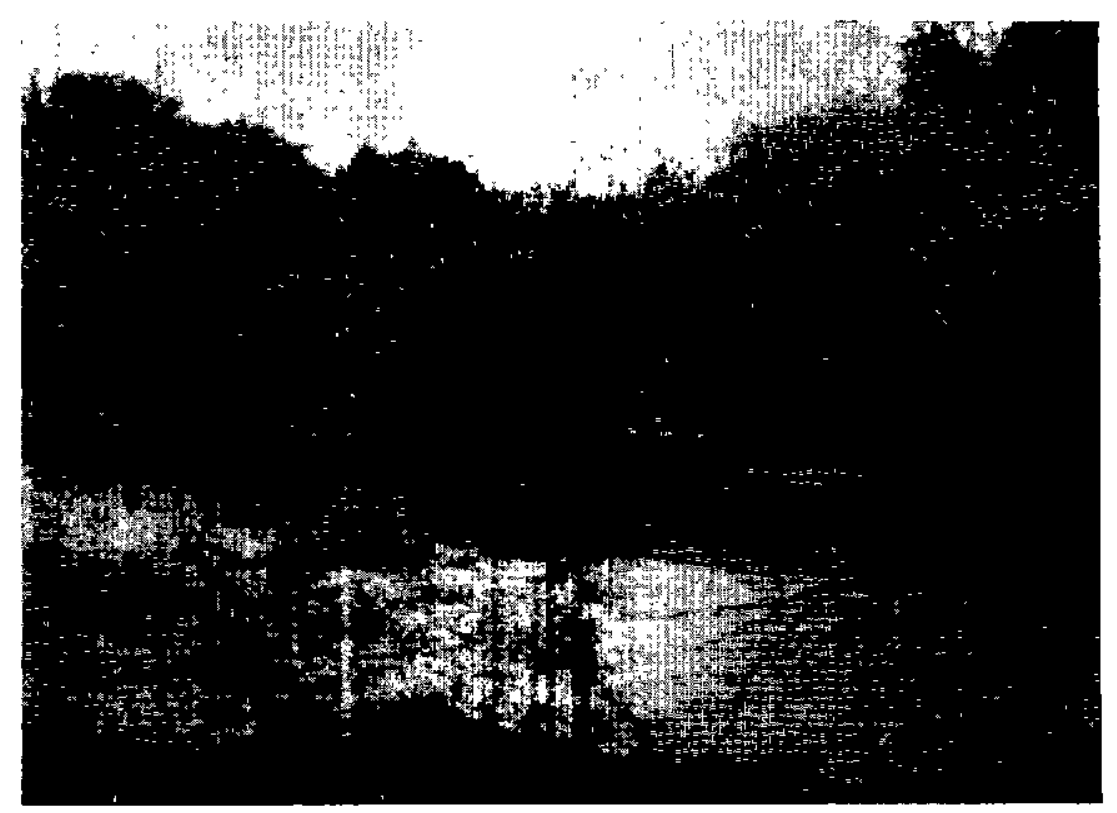

No 3. - Gîtes à Gi, lachinoides W. - Dro (Bas-Charı).

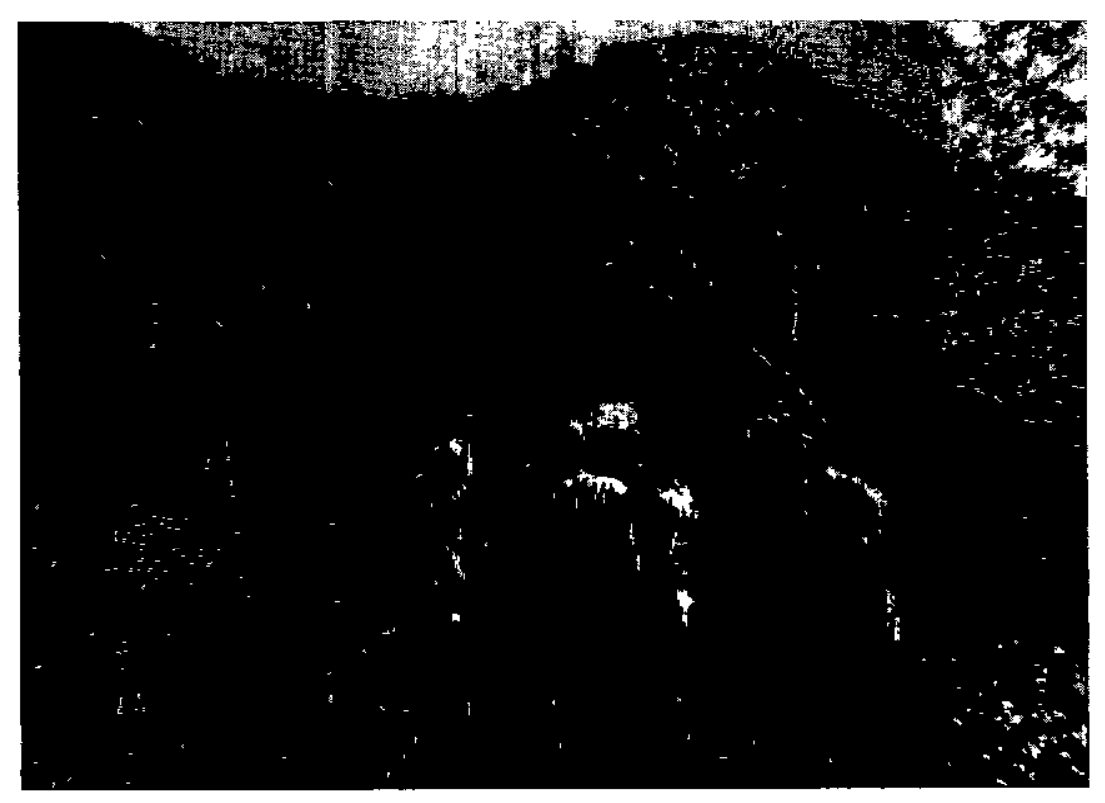

No 4. - Savane d̀ G! m submorsitans N. - Gabil-Margoula (Nord-Guéra) 


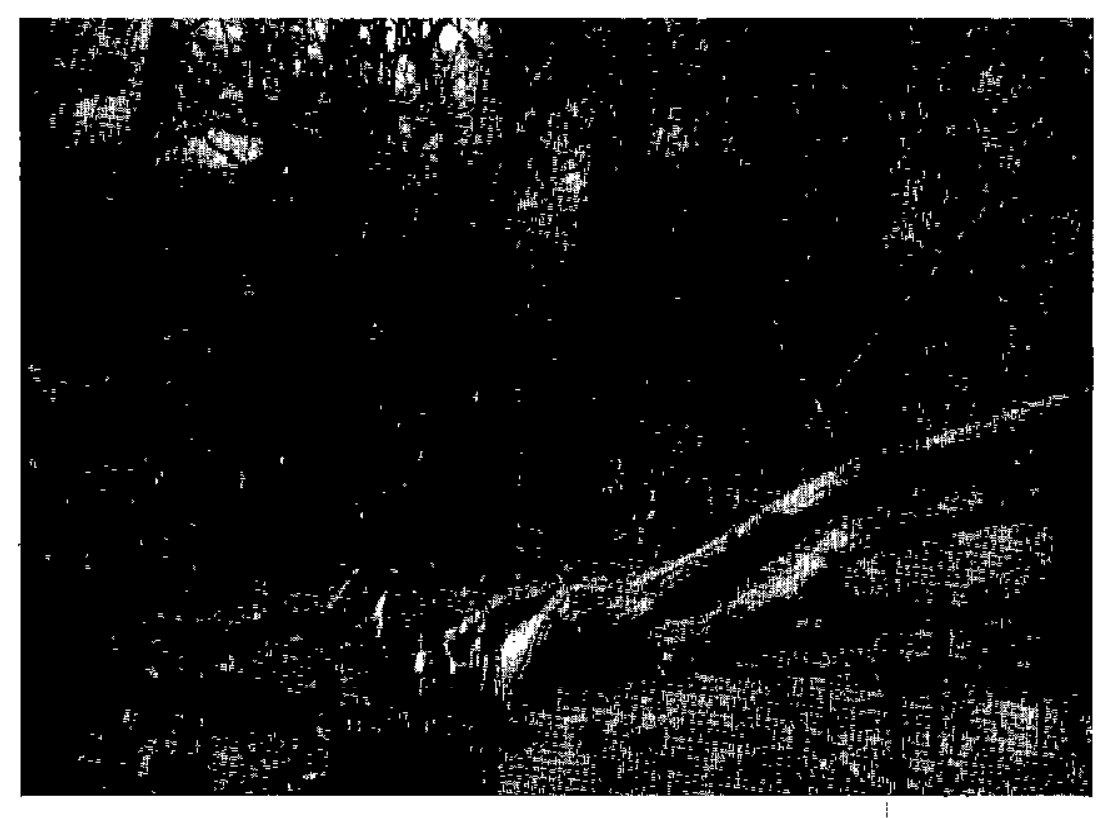

No 5. — Savane à GI. m. submorsitans N. - environs Timan (Sud-Guéra, abords du B. Salamat).

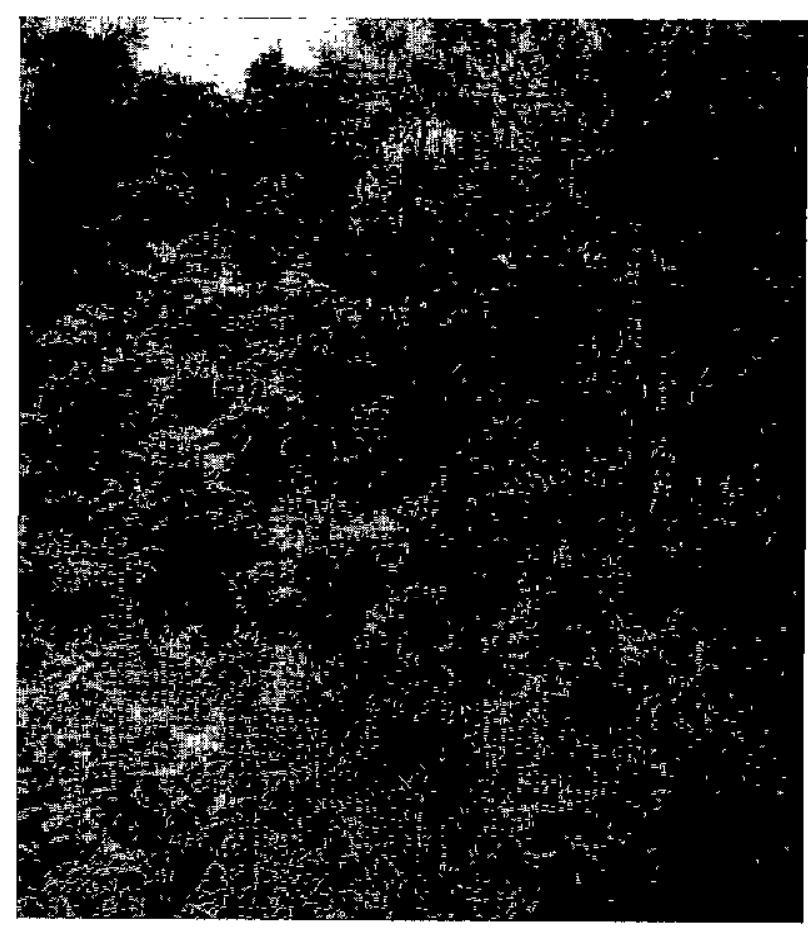

No 6. - Bordure de galerie forestière. Gîte à Glossina fuscipes fuscipes $N$. 


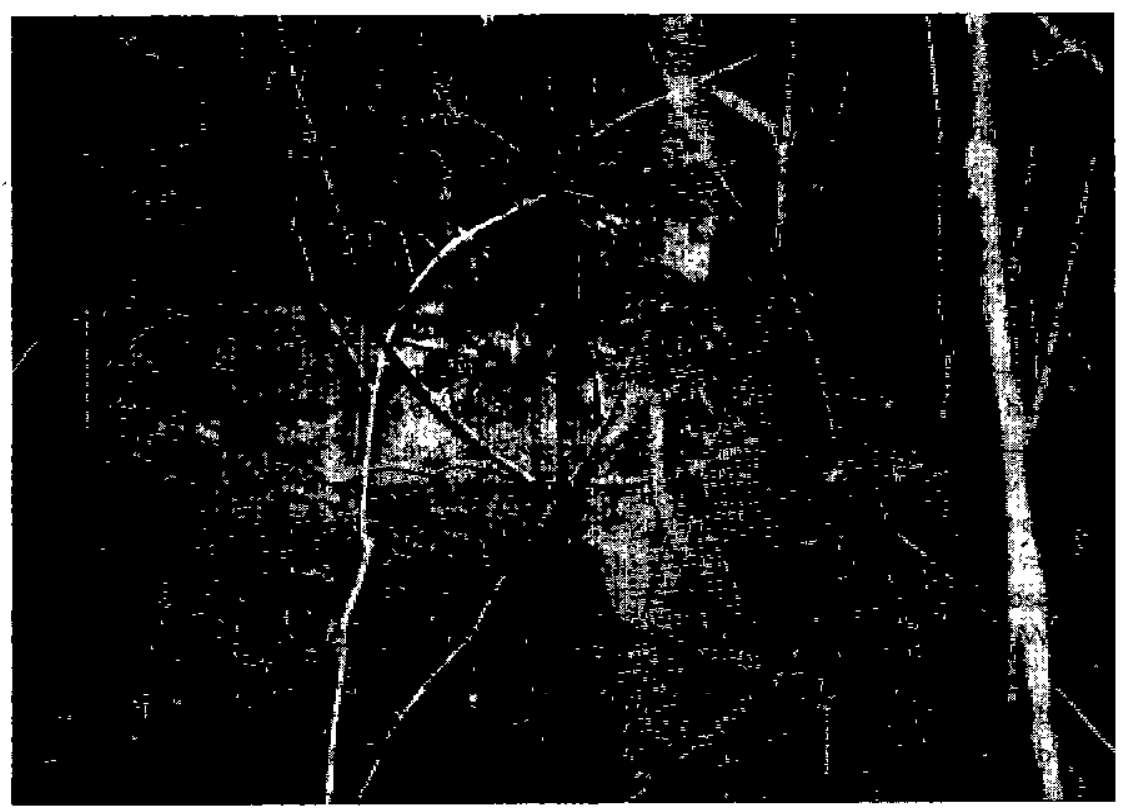

No 7. - Gîte à Glossina fuscipes fuscipes N. Lieu de ponte.

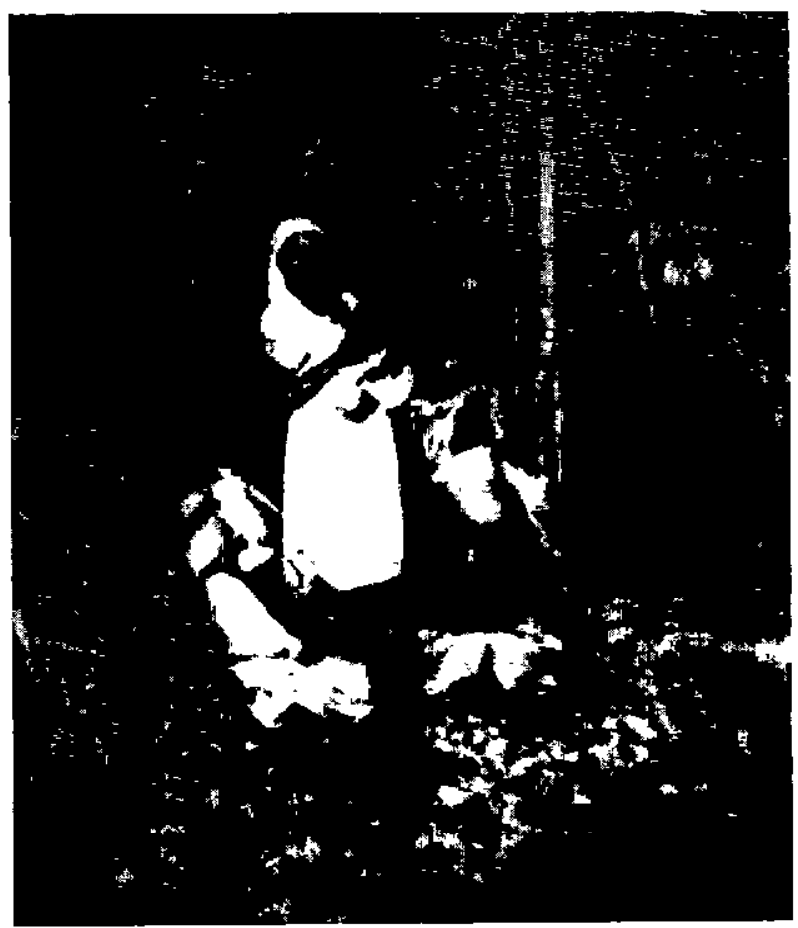

No 8. - Intérieur de ga!erie forestière. Gîte à Glossino fuscipes fuscipes N. 


\section{SUMMARY}

\section{Tse-Tse flies as vector of Trypanosomiasis in Chad}

Human and animal trypanosomiasis, as well as their principal, vector, tse tse flies, have been unceasingly the main subject of preoccupation for the medical and veierinary officers, since these came in Chad for the first time, at the beginning of the century.

- The study of the Glossinae vectors of Trypanosomiasis in Chad is presented as a statement of this important problem and is divided in 4 parts :

- In the first part, the incidence of Trypanosomiasis in Chad is reviewed and an historical background of the research works on this matter is given.

- The second part is entirely devoted to Glossinae. The results of old surveys, as well as the progress made in the knowledge of their geographical distribution. up to 1960, are pointed out. Then, the results of further surveys made since 1962 on the geographical distribution of the species found in Chad, are given. The geographical distribution of each of the three Chadian species Gl. tachinoides W., Gl. fuscipes fuscipes $N$. and Gl. marsitans submorsitans $N$. is also shown.

- In the third part, the main ecolagical observations which have been made during the surveys and which, up to a certain extend, can explain; the present distribution of the ise-tse flies, are recorded.

- 17 maps, one of which being comprehensive and insel, 3 tables, 2 diagrams, some pictures and 16 references complete this study of the Glossinae in Chad.

\section{RESUMEN}

\section{Las glosinas, vectores de las Tripanosomias/s en el Chad}

Desde su permanencia, al principio de este siglo, en Chad, los médicos y veterinarios estan preocupandose con las tripanosomiasis humanas o animales asi como con sus principales vectores, las glosinas, Se pasa en revista este importante problema de las glosinas, vectores de las tripanosomiasis en Chad Este estudio comprende 4 partes :

- En la primera, se nota la importancia de las tripanosomiasis en Chad y se historia las investigaciones concernientes a este asunto:

- En la segunda se tratan unicamente de las glosinas. En primer lugar se indican los resultados de encuestas anteriores y los progresos hechos en el conocimiento de su repartición hasta 1960. Luego se dan los resultados de investigaciones efectuadas desde 1962 concernientes a la repartición de las especies encontradas en Chad.

Se precisa tambien la repartición de cada una de las tres especies de Chad: $G$. tachinoides $W ., G$. fuscipes fuscipes $N, G$. morstans submorsitons $N$.

- La tercera parte nota las principales observaciones ecologicas hechas durante investigaciones que pueden explicar la repartición actualı de las glosinas.

- 17 mapas, de las cuales una general fuera-texto, 3 cuadros' 2 esquemas, fotografias y 16 referencias bib' lográficas acompañan este estudio sobre las glosinas en Chad. 


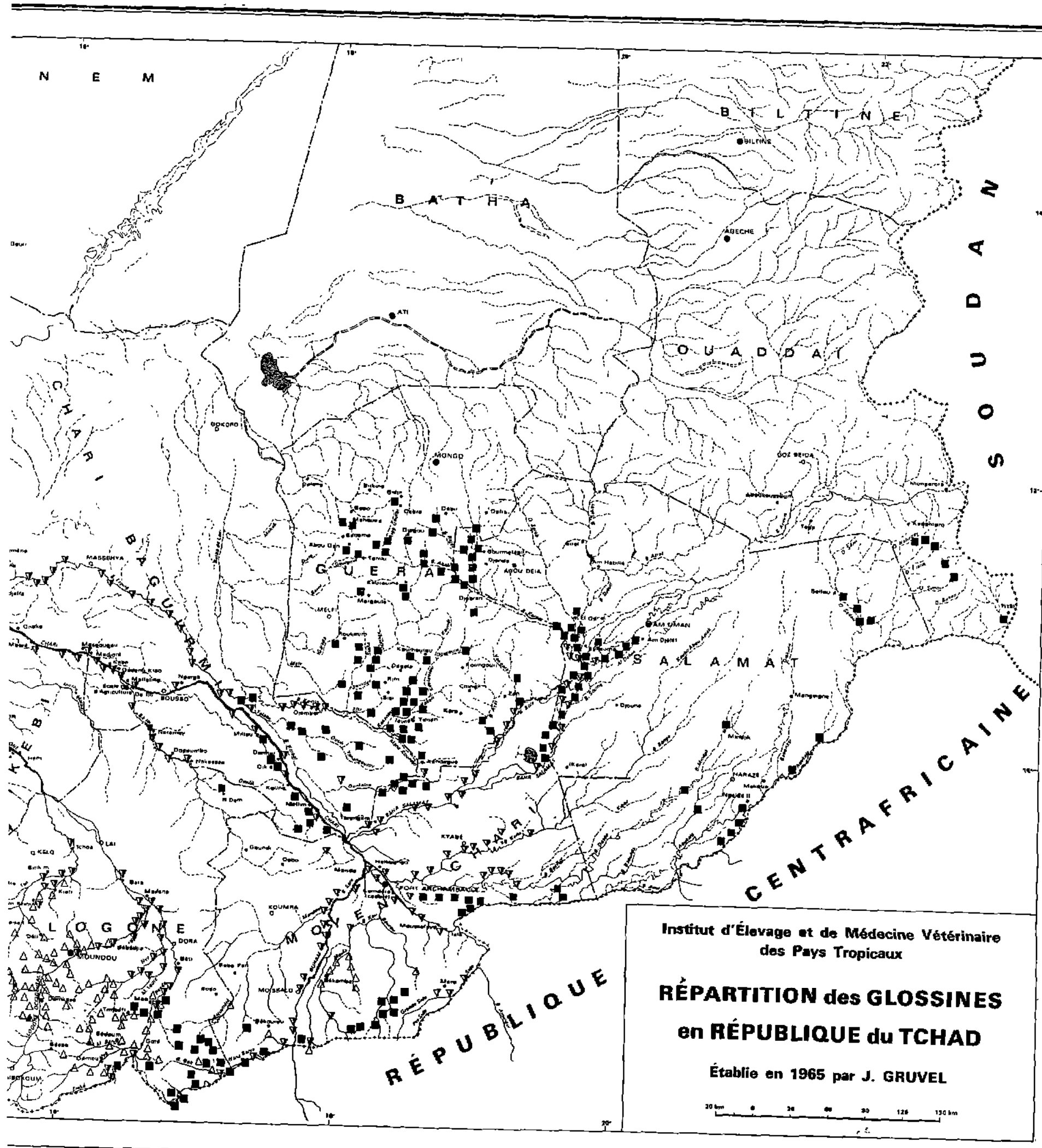




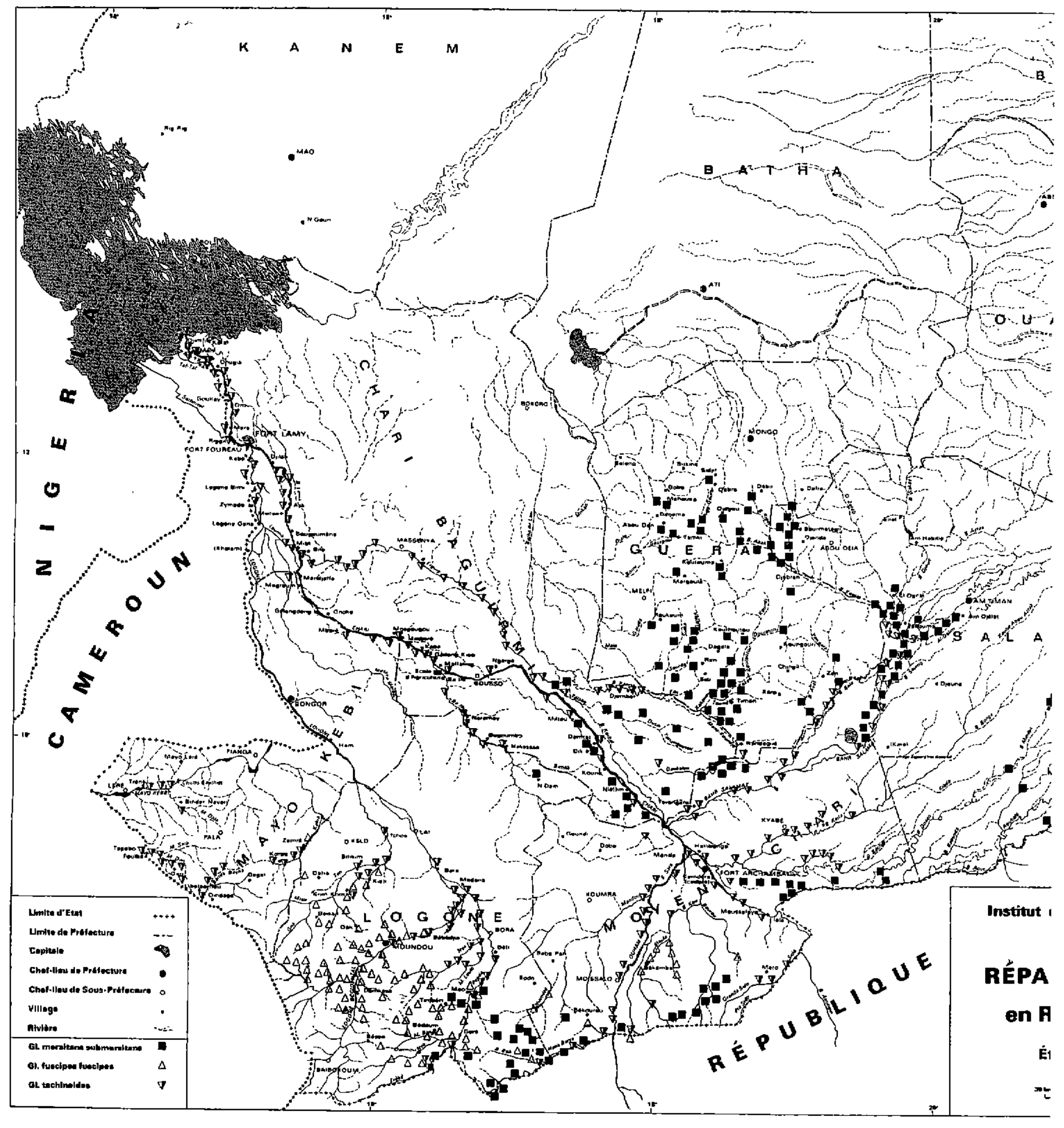




\section{BIBLIOGRAPHIE}

BOUILLIEZ (M.), - Contribution à l'étude et à la répartition de quelques affections parasitaires au Moyen-Chari. Bull. Soc. Path. Exot., 1916, 9, p. 143-165.

FINELLE (P.), ITARD (J.), YVORE(P.) et LACOT$T E(R$.$) . - Répartition des Glossines en Ré-$ publique Centrafricaine ; état actuel des connaissances. Rev. Elev. Méd. Vét. Pays Trop., 1963, 16, 3, 337-348.

FORD (J.). - The distribution of the vectors of african pathogenic trypanosomes. (Distribution des vecteurs de trypanosomes pathogènes africains). Bull. Org. Mond. Santé, $1963,28,5-6,653-669$.

GILLET (H.). - Végétation, Agriculture et Sol du Centre et du Sud du Tchad : feuilles de Milłou, Dagéla, Koumra, Moussafoyo. Journ. Agricult. Trop. et Bot. oppliquée, 1963, 10, 1-4.

KERANDEL (J.). - Trypanosomiases des Mammifères au Congo français. Bull. Soc. Path. Exot., 1908, I, p. 515.

KERMORGANT (A.). - La Nagana au Chari. Bull. Acad. Med., 1902, 47, p. 574-577.

MAILLOT (L.). - Carte de répartition des Glossines en A. E. F. O. R. S. T. O. M., 1953.

MAILLOT (L.). - Répartition des Glossines en A. E. F. Bull. Soc. Poth. exot., 1953, 46, 2, 195-197.
MAILLOT (L.). - Carte de répartition des Glossines dans les Etats de l'ancienne fédération d'A. E. F., O.R. S. T. O. M., 1961.

MALBRANT (R.) et DUGUÉ (J. M.). -- Les Trypa nosomiases animales en A. E. F. Recuell de Méd. Vét. Exot., 1933, 6, 2, 77-108.

MARTIN (G.), LEB氏EUF (A.) et ROUBAUD (E.). - Rapport de la Mission d'Etudes de la Maladie du sommeil au Congo français 19061908. Suciété de Géographie. Ed. Masson, Paris 1909.

MURAZ (G.). - Essai de détermination de la limite Nord de la Maladie du sommeil en A. E. F. Bull. Soc. Path. Exot., 1922, 15, 4, 253-280.

PECAUD (G.). - Les Trypanosomiases animales des Colonies françaises. Rev. Vét. Mirt., 1911, 3, p. 295-362.

PECAUD (G.). - Contribution à l'étude de la pathologie vétérinaire de la Colonie du Tchad. Bull. Soc. Patho. Exot., 1924, 3, 196207.

RECEVEUR (P.). - Répartition des Glossines dans le territoire du Tchad. Conf. Interafricane sur la tsé-tsé et les trypanosomiases, 1948, p. 338-344. Brazzaville (2-8 févr. 48).

Rapports annuels du Service de l'Elevage du Tchad; de 1911 à 1964. 